\title{
A Mathematical Modelling Approach for Managing Sudden Disturbances in a Three- Tier Manufacturing Supply Chain
}

\author{
Sanjoy Kumar Paul* \\ UTS Business School, University of Technology Sydney, Australia
}

\section{Ruhul Sarker, Daryl Essam}

School of Engineering and Information Technology, The University of New South Wales, Canberra, Australia

\section{Paul Tae-Woo Lee}

Ocean College, Zhejiang University, China

*Corresponding author. Email: $\underline{\text { sanjoy.paul@uts.edu.au }}$

\begin{abstract}
This paper aims to develop a recovery planning approach in a three-tier manufacturing supply chain, which has a single supplier, manufacturer, and retailer under an imperfect production environment, in which we consider three types of sudden disturbances: demand fluctuation, and disruptions to production and raw material supply, which are not known in advance. Firstly, a mathematical model is developed for generating an ideal plan under imperfect production for a finite planning horizon while maximizing total profit, and then we re-formulate the model to generate the recovery plan after happening of each sudden disturbance. Considering the high commercial cost and computational intensity and complexity of this problem, we propose an efficient heuristic, to obtain a recovery plan, for each disturbance type, for a finite future period, after the occurrence of a disturbance. The heuristic solutions are compared with a standard solution technique for a considerable number of random test instances, which demonstrates the trustworthy performance of the developed heuristics. We also develop another heuristic for managing the combined effects of multiple sudden disturbances in a period. Finally, a simulation approach is proposed to investigate the effects of different types of disturbance events generated randomly. We present several numerical examples and random experiments to explicate the benefits of our developed approaches. Results reveal that in the event of sudden disturbances, the proposed mathematical and heuristic approaches are capable of generating recovery plans accurately and consistently.
\end{abstract}


Keywords: supply chain disruption; quantitative recovery plan; sudden disturbance; heuristic; demand fluctuation.

\section{Introduction}

Managing a supply chain, which is a network of different entities who are working together to deliver the right product to the right customer at the right time, has become a daunting task for the businesses across the globe (Das et al. 2006; Huo et al. 2014). Nowadays, success of the organizations depends on effective and efficient supply chain management as with the trend towards outsourcing firms more and more focus on their core competencies (Narasimhan and Talluri 2009). Efficient and effective management of a supply chain requires proper planning, implementation and control of the operations of the supply chain (Ho et al. 2011). Although firms are working hard to ensure a smooth supply chain, supply chains operations have become more complex due to globalization, digitalization, and upgraded infrastructure, resulting in higher supply chain disturbances (Blome and Schoenherr 2011; Chaudhuri et al. 2013; C. Tang 2006). Both manufacturing and service firms, in their supply chain, facing supply chain disturbances (Blome and Schoenherr 2011), which have increased in the recent years (Christopher et al. 2011). For instance, a survey conducted in 2015 (Riglietti and Aguada 2018) in 426 organizations found that $74 \%$ of firms had experienced more than one supply chain disruption, with 6-20 disruptions per year for $15 \%$ of the companies. In general, manufacturing firms are facing more disturbances than service firms because every manufacturing firm needs to coordinate internal and external entities - such as suppliers, their own manufacturing plant, and retailers - to ensure smooth flow of products and proper services (Blome and Schoenherr 2011). All of these internal and external entities can be a potential source of supply chain disturbances, such as supply disruption from the supplier's end, production disruption in the manufacturing plant, and demand fluctuation from the retailer's end. Hence, additional attention on supply chain disturbance management is especially pertinent for manufacturing firms as opposed to service firms (Blome and Schoenherr 2011).

Supply chain disturbances bring many financial and non-financial losses for manufacturing organizations. For example, on March 17, 2000, a New Mexican company - Royal Phillips Electronics plant faced a lightning strike which caused a massive damage of millions of microchips. Ericsson, a Swedish multinational company which employed a single-sourcing strategy from the above-mentioned plant, lost more than U.S. \$400 million in potential revenue, and its market share reduced to 9\% from 12\% (Chopra and Sodhi 2004; Fang et al. 2013). A recent survey (Riglietti and Aguada 2018) also revealed that firms suffer heavily from monetary 
losses, which varied from $€ 50,000$ to $€ 500$ million due to these supply chain disruptions. The report also mentioned that supply chain disruptions reduce productivity for $58 \%$ of firms and reduce estimated revenue in $38 \%$ of companies. Moreover, companies suffering from supply chain disruption experienced a $10.28 \%$ abnormal decrease in shareholder value, and $33 \%-40 \%$ lower stock return compared to industry benchmarks (Hendricks and Singhal 2003, 2005). Previous studies (Chowdhury et al. 2016; Hendricks and Singhal 2003; Kim et al. 2015) also found that supply chain disturbances have an association with other measures of financial performance such as a negative association with return on sales and return on assets, and a positive association with the cost of production and level of inventory. In addition to the financial losses, manufacturing firms suffer from different non-financial losses due to supply chain disturbances. For instance, supply chain disturbances harmed the reputation of $27 \%$ firms (Riglietti and Aguada 2018) and reduced employment in the firms (Thun and Hoenig 2011). Considering the significant negative impact of supply chain disturbances on the financial and non-financial measures of performance of manufacturing firms, it has become crucial to develop proper strategies for managing supply chain disturbances of manufacturing firms (Ambulkar et al. 2015; Craighead et al. 2007).

The impact of supply chain disturbances can be minimized through proper planning and risk management strategies. Several previous studies over the past two decades have developed different disturbance mitigation and management strategies such as buffer stock (Mishra et al. 2016) supplier development, ensuring contractual governance, multiple sourcing, supply chain collaboration, etc. for the manufacturing supply chain. However, the majority of supply chain disturbances occur suddenly with unique characteristics (Chopra and Meindl 2007; Wakolbinger and Cruz 2011), hence pre-determined mitigation strategies may not be appropriate to fully and timely recover from the sudden supply chain disturbance. Therefore, firms should have an effective recovery planning approach to reduce the impact of a sudden disruption (Tomlin 2006). An effective recovery planning model can help a manufacturing firm reduce the impact of the disruption which will, in turn, enhance the viability of the business.

Previous studies have provided few supply chain recovery models to counter supply chain disturbances. However, there is a lack of research that evaluates operational and planning models rigorously under more complex conditions (Fang et al. 2013). The majority of existing studies that developed quantitative supply chain models only considered ideal supply chain settings, while very few previous studies provided recovery models dealing with disturbances, on a real-time basis (Paul et al. 2016a). Moreover, those who developed models for 
manufacturing supply chains that could reactively manage disturbance events only considered a single disturbance (Ho et al. 2015). However, in reality, firms may suffer from multiple supply chain disturbances simultaneously, hence it is important to develop a heuristic that can approximate the recovery plan for multiple types of supply chain disturbances. But existing literature couldn't capture the effect of multiple sudden supply chain disturbances, and such there is no quantitative model and solution approach for developing recovery plan considering the effect of multiple sudden disturbances in a three-tier supply chain system (Paul et al. 2016a). Inspired by this fact, in this paper we attempt to develop mathematical and heuristic solutions for generating recovery plans to manage multiple types of supply chain disturbances by considering separate and combined effects which will reduce the effect of disturbance on the operational activities of the firm.

The main objective of this research is to develop a quantitative model for generating recovery plans for three types of sudden supply chain disturbances - supply disruption, production disruption, and demand fluctuation. Although existing commercial software might be used to solve the developed mathematical model, use of this software in practice will be very expensive (Hishamuddin et al. 2012). Besides, the computation can be very complex in the case of solving multiple types of supply chain disturbances simultaneously. Therefore, we develop heuristics which on the one hand are cost-effective and on the other not overly complex, to accurately estimate the optimal recovery plan for each of the three types of supply chain disturbances. Moreover, we develop another heuristic that can precisely consider the effect of multiple supply chain disturbances in a combined manner. Existing literature cannot help a supply chain and operational manager to formulate the right recovery plan for managing the effect of multiple types of sudden supply chain disturbances. Further, by helping in taking the right decisions at the right time, this paper has the potential to help a supply chain and operational manager to formulate the right strategy and reduce the effect of supply chain disturbance on the operational activities of the firm which will, in turn, increase the customer retention rate of the firms.

The paper proceeds as follows. In Section 2 we review related literature, and the problem description is presented in Section 3. Mathematical modeling to generate a recovery plan is formulated in Section 4. The solution approaches and simulation model are provided in Sections 5 and 6 respectively. Section 7 discusses the random experimentations and analyses of results. Finally, we provide conclusions and future research directions in Section 8. 


\section{Literature review}

Supply chain sudden disturbances are unwanted, unusual triggering events associated with the supply chain that materializes somewhere in the supply chain or its external environment, in which its outcomes significantly threaten the regular operations of a business (Wagner and Bode 2008). These sudden disturbances, which cannot be predicted, can be associated with anyone of three main streams - upstream, midstream, and downstream - of supply chain (Chowdhury et al. 2016; Handfield and McCormack 2007). Upstream disturbances - also known as supply disruptions - are unusual incidents linked with sourcing material from suppliers that disrupts the expected sourcing performance, such as quality of material, quantity of material, and delivery time of material (Teresa Wu et al. 2006; G. A. Zsidisin and Smith 2005). Midstream disturbances - also termed production disruptions - are sudden events that disturb a firm's internal production systems (Lockamy III and McCormack 2010). Downstream disturbances - also known as demand fluctuations - are the sudden incidents that cause fluctuations in customer demand, which result in imbalances between demand and supply (Nagurney et al. 2005). A few recent review papers (Fahimnia et al. 2015; Ivanov et al. 2017; Paul et al. 2016a; Snyder et al. 2016) have discussed the literature related to supply chain risk and disruption management. However, for the literature review related to this research, we focus on recent papers related to recovery planning for supply chain disturbance management.

Supply chain disturbances can result from both major global events and less global events such as fire (such as the earlier Philips example), traffic jams, machine breakdowns, and inappropriate forecasting (Fang et al. 2013). Several previous studies (Chopra and Sodhi 2004; Christopher and Peck 2004; Ho et al. 2015; O. Tang and Nurmaya Musa 2011) identified the different types of supply chain disturbances that a practitioner must consider when planning management strategies, and the causes of these supply chain disturbances (Chopra and Sodhi 2004), and differentiated between sudden disturbances (catastrophic events that have low probability but high impact) and operational risk (also known as recurrent risk) such as quality and quantity problems. Later, a few studies (Chen et al. 2013; Chowdhury et al. 2016; Sheffi and Rice 2005) also made a similar distinction. In this paper, to provide a meaningful planning and strategy to recover from sudden disturbances, we develop recovery models for a manufacturing supply chain that considers three types of sudden disturbances - demand fluctuation, production disruptions, and raw material supply disruptions.

A reasonable number of research studies on supply chain disturbance management can be found in the literature. All these studies provide several meaningful suggestions and strategies for 
managing disturbances in complex supply chain networks (Wieland and Wallenburg 2012). Tomlin (2006) categorized all these supply chain disturbance management approaches into three areas: mitigation, contingency, and passive acceptance. In mitigation strategies, firms take actions before the occurrence of the risk to either reduce the probability of occurrence or to reduce the impact of risk, such as through buffer stock or supplier development. Contingency plans are those in which firms take actions when a risk occurs, such as contingency procurement from a back-up supplier. However, rather than adopting any mitigation or contingency planning, firms accept the risk when the costs of dealing with a disturbance out-weigh the losses of accepting the impact of that disturbance. The majority of existing studies in the domain of supply chain disturbance management focus on developing mitigation strategies rather than formulating models or approaches for rapid recovery after the occurrence of disturbances (Ho et al. 2015). Tang (2006) proposed certain "robust" policies for mitigating disturbances in supply chain system which could enable a supply chain to: (i) efficiently manage inherent fluctuations regardless of the occurrence of a major disruption and, (ii) become more resilient in the face of a major disruption. Craighead et al. (2007) provided six propositions which clearly state that increasing knowledge regarding the factors of supply chain disturbances could potentially reduce the number of disturbances. Designing appropriate and complete contractual governance is suggested by Xiao et al. (2007) to properly coordinate the supply chain with demand disruptions in the setting of one manufacturer and two competing retailers. Recently, a risk management and mitigation model (Manuj and Mentzer 2008) and an improved risk measurement and prioritization method (Bradley 2014) were proposed to find the insight characteristics of supply chain risks.

Several studies in the area of supply chain disturbance management also developed mathematical models to ensure robust and efficient supply chains (Snyder et al. 2016). Wu et al. (2007) developed a network based model for determining the changes or disruptions propagation. Recently, Atoei et al. (2013) designed a reliable capacitated supply chain model by considering random disruptions in distribution centers (DCs). Some authors also evaluated - by using a mathematical model - the single or multiple sourcing strategies in the presence of supply chain disruptions, and there is a consensus that dual or multiple sourcing strategies outperform single-sourcing strategies (Burke et al. 2007; Fang et al. 2013; Sarkar et al. 2013; Silbermayr and Minner 2014; Yu et al. 2009). Some other supply chain disturbance management models can be found in other studies (Bandaly et al. 2016; Paul and Rahman 2018; Paul et al. 2015, 2019; Serel 2015; Xu et al. 2016). 
Although previous studies extensively examined mitigation strategies for supply chain disturbance, there is a lack of research in the stream of supply chain disturbance management focused on recovery strategies. Wakolbinger \& Cruz (2011) pointed out that it was difficult to predict supply chain disturbances in advance, hence taking the right mitigation strategies for those disturbances is more challenging. Therefore, many previous studies (Gupta et al. 2015; Tomlin 2006; G. a. Zsidisin et al. 2000) suggested developing and implementing effective recovery plans to enable supply chains to quickly return to their original condition after the occurrence of a disturbance. Oke and Gopalakrishnan (2009) identified strategies to overcome supply chain vulnerability, and concluded that putting recovery plans in place was the key to mitigating supply chain disturbances. Few previous studies have addressed reactive strategies for supply chain disturbances. A model-based framework was suggested by Adhitya et al. (2007) for rescheduling operations in the occurrence of supply chain disturbances. Eisenstein (2005) addressed disturbances in electronic lot scheduling when the original schedule was fixed and focused on contingency policy after the occurrence of one or more shocks through a new class of policies called dynamic produce-up-to policies, that used idle time and re-established the target idle time during recovery. Xia et al. (2004) proposed a general production and inventory disruption management model in which they included a cost for deviations of the revised plan from the normal plan. Hishamuddin et al. (2012) extended the model proposed in (Xia et al. 2004), and developed a disruption recovery approach for an economic production quantity model, which obtained a real-time revised plan within a specified time window. Recently, the backorder and lost sales concept was further applied to develop a recovery model for managing sudden supply disturbance in a three-stage supply chain with multiple raw material suppliers and retailers (Paul et al. 2016a; Paul et al. 2014b). This concept was also applied to develop a disturbance management model for managing sudden disruptions in a single-stage imperfect (Paul et al. 2013), a two-stage imperfect (Paul et al. 2014c), a three-stage mixed (Paul et al. 2015) production-inventory system, a three-stage supply chain system (Paul et al. 2017), and for managing sudden demand fluctuations in a manufacturer-retailer system (Paul et al. 2014a). Besides, Yang et al. (2005) also addressed a recovery planning approach for production and stock control policies. Some other disturbance recovery models can be found in other studies (DuHadway et al. 2017; Hasan et al. 2015; Ivanov et al. 2014, 2016; Paul et al. 2017). In the case of a sudden disturbance, recovery planning could work better than mitigation approaches, and there is limited research which develops recovery planning models for supply chain disturbances; in this study, we develop recovery models for managing sudden disturbances in a manufacturing supply chain. 
A disturbance is a common event in a supply chain environment and is a concern because it can cause companies to suffer both financial and reputational losses. As a sudden disturbance event cannot be predicted, the whole plan of an organization can be distorted and cause discontinues the production and delivery and unfulfilled demand. Hence, if a system is disturbed suddenly for a certain duration of time, it is essential to revise its some future plan, until it returns to its normal plan (Hishamuddin et al. 2012). In case of sudden disturbance, a proper disturbance recovery plan can assist to minimize a company's losses and uphold its reputation. However, in the literature there are very few studies that developed approaches for obtaining a recovery plan after a sudden disturbance (Paul et al. 2016a). Moreover, studies in the literature that provide recovery models for supply chain disruptions only consider a single disturbance (Paul et al. 2016a) in formulating plans, while in a real-life situation firms can suffer from multiple disturbances at the same time. Although some existing papers proposed some heuristics to solve models, very few of these studies developed a combined both heuristic and simulation approach to bring the developed approach closer to real-life processes. In this study, we attempt to fill up above identified research gaps and develop mathematical, heuristic and simulation approaches which bring a disturbance management problem closer to the real-world, and perform a great deal of random experimentation to validate the heuristics and analyze the results.

The contributions of this research are summarized as follows.

i. Formulation of a mathematical model to generate recovery plan of either one or a combination of three sudden disturbances- supply disruption, production disruption, and demand fluctuation - in a supply chain system.

ii. Development of new and efficient heuristic solutions to generate a recovery plan for these disturbances by considering both single and combined effects.

iii. Development of a simulation approach, and conduct of random experiments.

\section{Problem description}

In this section, we describe the disturbance problem considered in this research.

For a better understanding of the disturbance management problem, we provide the definitions of the different terms used in this study as follows.

i. Process reliability: percentage of faultless products produced in the system (Cheng 1989).

ii. Demand fluctuation: any kind of variation (either positive or negative) in product demand in a period ( Paul et al. 2014c). 
iii. Production disruption: any kind of interruption in the production system (Paul et al. 2014b); for example, power cut, machine breakdown, labor strike, etc.

iv. Supply disruption: any kind of stoppage to the raw material supply that may be caused by an unavailability, delay, or any other form of interruption (Paul et al. 2016b).

v. Ideal plan: a plan for production, supply, and delivery developed under no disturbance condition.

vi. Recovery plan: it is essential to revise the plan for a finite future period, after a sudden disturbance in the system, until the system coming back to its ideal plan (Paul et al. 2016b).

vii. Backorder: after the occurrence of a disturbance, a certain amount of demand that cannot be fulfilled on time but will be supplied at a later date (Paul et al. 2014b).

viii. Lost sales: if, after the occurrence of a disturbance, customers will sometimes not wait for stock to be refilled, and demand is lost (Paul et al. 2014b).

ix. Loss of demand: if the product demand is lessened suddenly, the system has to reduce the future production quantity to compensate for lessened demand (Paul et al. 2014c).

We use the following notations in this study.

$n \quad$ Number of planning periods in planning horizon

$D_{i} \quad$ Demand of period $i$

$P \quad$ Maximum production capacity of each period

$B_{i} \quad$ Beginning inventory in period $i$

$B_{n+1}$ Beginning inventory which should be kept in period $(n+1)$

$E_{i} \quad$ Ending inventory in period $i$

$A P_{i} \quad$ Actual production in period $i$

$S C_{i} \quad$ Spare capacity in period $i$

$R_{i} \quad$ Quantity received by retailer at period $i$

$N \quad$ Number of units of raw material necessary for one unit final product

$A \quad$ Set-up cost at the manufacturing plant

$r \quad$ Process reliability of manufacturing plant

$R M_{i} \quad$ Raw material supply quantity for period $i$

$C_{p} \quad$ Production cost per unit

$C_{d} \quad$ Delivery cost per unit

$C_{r} \quad$ Raw material cost per unit

$H_{1} \quad$ Raw material holding cost per unit per period 
$\mathrm{H}_{2} \quad$ Ending inventory holding cost per unit

$C_{L} \quad$ Cost per unit due to decrease of demand

$C_{I} \quad$ Inspection cost as a percentage of the production cost

$C_{R} \quad$ Rejection cost per unit

$S \quad$ Selling price per unit

$B \quad$ Backorder cost per unit per period

$L \quad$ Lost sales cost per unit $=$ revenue loss per unit + cost of reputation loss per unit

$X_{i} \quad$ Production quantity in period $i$ in recovery plan

$Y_{i} \quad$ Delivery quantity in period $i$ in recovery plan

$Z_{i} \quad$ Raw material quantity in period $i$ in recovery plan

$b_{i} \quad$ Beginning inventory in recovery plan

$e_{i} \quad$ Ending inventory in recovery plan

\section{Demand fluctuation parameter}

$\delta \quad$ Demand fluctuation amount

\section{Production disruption parameters}

$t_{s} \quad$ Disruption start time as a fraction of duration of period

$T_{d p} \quad$ Disruption duration as a fraction of duration of period $\left(\leq 1-t_{s}\right)$

$q \quad$ Pre-disruption production quantity $=t_{s} * P$

\section{Supply disruption parameter}

$T_{d s} \quad$ Disruption duration as a fraction of duration of period $(\leq 1)$

\subsection{Problem statement}

In this section, the different disturbance problems that occur in a real-life supply chain system are described and presented. These are shown in Figure 1. We consider that a sudden demand fluctuation can happen at the retailer end, a sudden production disruption at the manufacturing plant and a sudden supply disruption at the supplier end. After a sudden disturbance occurs in a system, the production, supply, and delivery plan has to be revised for a finite future period, so that the effect of the disturbance is minimized; in other words, total profit is maximized. 


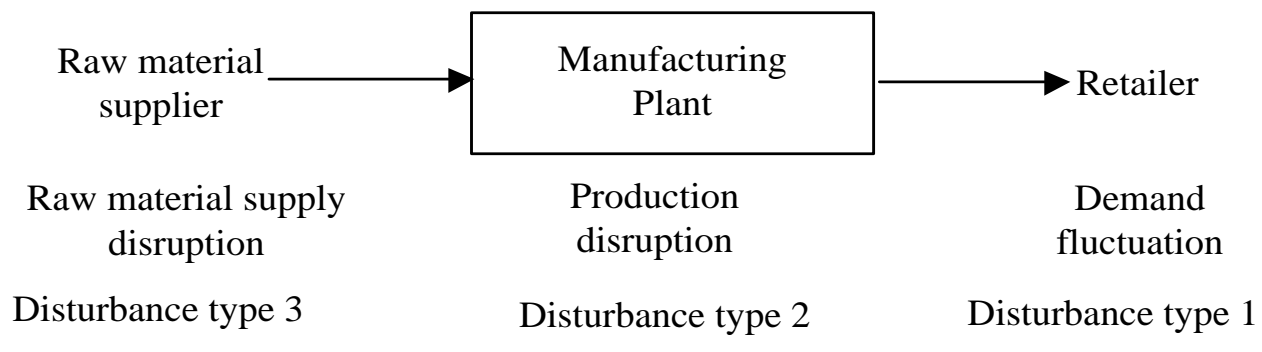

Figure 1: Disturbances in a manufacturing supply chain

In this system, we first develop the ideal production, supply, and delivery plan for $n$ periods under an imperfect production system, which is updated after each period for the next $n$ periods on a rolling horizon basis. We use the term process reliability $(r)$ to express an imperfect production environment (Cheng 1989). The ideal plan is presented in Table 1, where the decision variables are $A P_{i}, R_{i}, R M_{i}, B_{i}$ and $E_{i}$, and the total profit is maximized.

Table 1: Ideal plan for $n$ periods

\begin{tabular}{|c|c|c|c|c|c|}
\hline \multirow{2}{*}{ Variable } & \multicolumn{5}{|c|}{ Period } \\
\cline { 2 - 6 } & 1 & 2 & 3 & $\ldots \ldots$ & $n$ \\
\hline Demand $\left(D_{i}\right)$ & $D_{1}$ & $D_{2}$ & $D_{3}$ & $\ldots \ldots$ & $D_{n}$ \\
\hline $\begin{array}{c}\text { Production } \\
\text { capacity }(P)\end{array}$ & $r P$ & $r P$ & $r P$ & $\ldots \ldots$ & $r P$ \\
\hline $\begin{array}{c}\text { Actual } \\
\text { production } \\
\left(A P_{i}\right)\end{array}$ & $A P_{1}$ & $A P_{2}$ & $A P_{3}$ & $\ldots \ldots$ & $A P_{n}$ \\
\hline $\begin{array}{c}\text { Beginning } \\
\text { inventory }\left(B_{i}\right)\end{array}$ & $B_{1}$ & $A P_{1}+B_{1}-R_{1}$ & $\sum_{j=1}^{2} A P_{j}-\sum_{j=1}^{2} R_{j}$ & & $\sum_{j=1}^{n-1} A P_{j}-\sum_{j=1}^{n-1} R_{j}$ \\
\hline $\begin{array}{c}\text { Ending } \\
\text { inventory }\left(E_{i}\right)\end{array}$ & $-R_{1}+B_{1}$ & $\sum_{j=1}^{2} A P_{j}-\sum_{j=1}^{2} R_{j}$ & $\sum_{j=1}^{3} A P_{j}-\sum_{j=1}^{3} R_{j}$ & $\ldots \ldots$ & $\sum_{j=1}^{n} A P_{j}-\sum_{j=1}^{n} R_{j}$ \\
\hline $\begin{array}{c}\text { Received by } \\
\text { retailer }\left(R_{i}\right)\end{array}$ & $\begin{array}{c}B_{1}+A P_{1} \\
-E_{1}\end{array}$ & $B_{2}+A P_{2}-E_{2}$ & $B_{3}+A P_{3}-E_{3}$ & $\ldots \ldots$ & $B_{n}+A P_{n}-E_{n}$ \\
\hline $\begin{array}{c}\text { Raw material } \\
\text { quantity }\left(R M_{i}\right)\end{array}$ & $R M_{1}$ & $R M_{2}$ & $R M_{3}$ & $\ldots \ldots$ & $B_{1} R M_{n}$ \\
\hline
\end{tabular}

Finally, this paper develops a recovery plan - which is actually a reactive mitigation -after the occurrence of a sudden disturbance. In real-life supply chain environment, a sudden disturbance can occur at any time. After such an occurrence, the plan must be revised for a finite period in the future so that losses can be minimized and the system returns to its ideal plan as quickly as possible. After the occurrence of a disturbance, $X_{i}, Y_{i}, Z_{i}, b_{i}$ and $e_{i}$ are changed to obtain the 
recovery plan presented in Table 2, while the objective is still to maximize total profit. Here, $X_{i}, Y_{i}, Z_{i}, b_{i}$ and $e_{i}$ are decision variables in the recovery plan.

Table 2: Recovery plan after a disturbance occurs

\begin{tabular}{|c|c|c|c|c|c|}
\hline \multirow{2}{*}{ Variable } & \multicolumn{5}{|c|}{ Period } \\
\hline & 1 & 2 & 3 & $\ldots \ldots$ & $n$ \\
\hline $\begin{array}{l}\text { Production } \\
\left(X_{i}\right)\end{array}$ & $X_{1}$ & $X_{2}$ & $X_{3}$ & ..... & $X_{n}$ \\
\hline $\begin{array}{l}\text { Received by } \\
\text { retailer }\left(Y_{i}\right)\end{array}$ & $Y_{1}$ & $Y_{2}$ & $Y_{3}$ & $\cdots \cdots$ & $Y_{n}$ \\
\hline $\begin{array}{l}\text { Beginning } \\
\text { inventory } \\
\quad\left(b_{i}\right)\end{array}$ & $b_{1}$ & $X_{1}+b_{1}-Y_{1}$ & $\sum_{j=1}^{2} X_{j}-\sum_{j=1}^{2} Y_{j}$ & & $\sum_{\substack{j=1 \\
+b_{1}}}^{n-1} X_{j}-\sum_{j=1}^{n-1} Y_{j}$ \\
\hline $\begin{array}{c}\text { Ending } \\
\text { Inventory } \\
\left(e_{i}\right)\end{array}$ & $X_{1}+b_{1}-Y_{1}$ & $\sum_{\substack{j=1 \\
+b_{1}}}^{2} X_{j}-\sum_{j=1}^{2} Y_{j}$ & $\sum_{\substack{j=1 \\
+b_{1}}}^{3} X_{j}-\sum_{j=1}^{3} Y_{j}$ & & $\sum_{\substack{j=1 \\
+b_{1}}}^{n} X_{j}-\sum_{j=1}^{n} Y_{j}$ \\
\hline $\begin{array}{c}\text { Raw } \\
\text { material } \\
\text { quantity } \\
\left(Z_{i}\right) \\
\end{array}$ & $Z_{1}$ & $Z_{2}$ & $Z_{3}$ & ..... & $Z_{n}$ \\
\hline
\end{tabular}

\subsection{Assumptions of the study}

In this paper, we make the following assumptions:

i. The total production capacity is greater than its demand rate.

ii. The system produces a single item.

iii. The total cost of interest and depreciation $F(A, r)$ is taken from the following function (Cheng 1989):

$$
F(A, r)=a A^{-b} r^{c}
$$

where $a, b$, and $c$ are positive constants selected to offer the best fit of the cost function (Cheng 1989).

iv. The recovery plan considers both backorder and lost sales to recover from a sudden disturbance. Supplier, manufacturer, and customers agree with these policies.

\section{Mathematical modeling}

A mathematical model is developed in this section for managing a single sudden disturbance caused by a demand fluctuation, production disruption, or supply disruption. At first, we present a model to generate a supply chain plan under ideal condition. Then, we re-formulate a 
mathematical model to generate a recovery plan as a constrained mathematical programming problem. The objective is to maximize total profit, which is derived from the revenue - obtained from acceptable items, minus relevant costs. In the recovery plan, we consider the revised quantities of production, delivery, and supply in each period as decision variables.

\subsection{Modeling for ideal plan}

In the ideal plan, we calculate the costs for production, rejection, inspection (Paul, Azeem, Sarker \& Essam 2014), depreciation (Cheng 1989), holding, delivery, and raw material purchases, as well as the revenue from acceptable items. Then, we develop a model as a constrained mathematical optimization problem in which the objective is to maximize total profit subject to constraints from capacity, delivery, inventory, and product demand.

\section{Calculations of different costs and revenue}

Total production cost $=\frac{C_{p}}{r} \sum_{i=1}^{n} A P_{i}$

Total rejection cost $=C_{R}\left(\frac{1}{r}-1\right) \sum_{i=1}^{n} A P_{i}$

Total inspection cost $=\frac{C_{I} C_{p}}{r} \sum_{i=1}^{n} A P_{i}$

Cost of interest and depreciation $=n a A^{-b} r^{c}$

Raw material holding cost $=\frac{1}{2} H_{1} \sum_{i=1}^{n} R M_{i}=\frac{1}{2 r} H_{1} N \sum_{i=1}^{n} A P_{i}$

Total raw material cost $=\sum_{i=1}^{n} C_{r} R M_{i}=\frac{N C_{r}}{r} \sum_{i=1}^{n} A P_{i}$

Total delivery cost $=\sum_{i=1}^{n} C_{d} R_{i}$

Total ending inventory holding cost $=H_{2} \sum_{i=1}^{n} E_{i}$

Total revenue $=S \sum_{i=1}^{n} A P_{i}$

\section{Final mathematical model}

Total profit $=$ total revenue - total costs, is the objective function and is obtained by using equations (1) - (9) and presented in equation (10).

$$
\begin{aligned}
T P=S \sum_{i=1}^{n} A P_{i} & \\
& -\left[\frac{C_{p}}{r} \sum_{i=1}^{n} A P_{i}+C_{R}\left(\frac{1}{r}-1\right) \sum_{i=1}^{n} A P_{i}+\frac{C_{I} C_{p}}{r} \sum_{i=1}^{n} A P_{i}+n a A^{-b} r^{c}\right. \\
& \left.+\frac{1}{2 r} H_{1} N \sum_{i=1}^{n} A P_{i}+\frac{N C_{r}}{r} \sum_{i=1}^{n} A P_{i}+\sum_{i=1}^{n} C_{d} R_{i}+H_{2} \sum_{i=1}^{n} E_{i}\right]
\end{aligned}
$$


Here,

$R_{i}=B_{i}+A P_{i}-E_{i} ; \forall i$

$B_{i}=\sum_{j=1}^{i-1} A P_{j}-\sum_{j=1}^{i-1} R_{j}+B_{1} ; \forall i \neq 1$

$E_{i}=\sum_{j=1}^{i} A P_{j}-\sum_{j=1}^{i} R_{j}+B_{1} ; \forall i$

$R M_{i}=N * \frac{A P_{i}}{r}$

subject to constraints presented in equations (11) - (17).

$E_{i} \geq 0 ; \forall i$ [Ending inventory cannot be negative]

$B_{i} \geq 0 ; \forall i$ [Beginning inventory cannot be negative]

$E_{n}=B_{n+1}\left[\right.$ Beginning inventory for $(n+1)^{\text {th }}$ period]

$\sum_{i=1}^{n} A P_{i}=\sum_{i=1}^{n} D_{i}-B_{1}+B_{n+1}$ [Total production must be equal to total demand]

$A P_{i} \leq r P$ [Actual production must be less than maximum production capacity]

$R_{i}=D_{i}$ [Delivery quantity must be equal to demand]

$A P_{i}, R_{i}$ and $R M_{i} \geq 0$ [Non-negativity constraint]

\subsection{Modeling for recovery plan}

In this section, a mathematical model is developed for generating a recovery plan after a sudden demand fluctuation, with plans for sudden production and supply disruptions presented in Appendix A and Appendix B respectively.

\subsubsection{Mathematical model for sudden demand fluctuation}

The mathematical model is formulated for generating the recovery plan after a demand fluctuation. The model considers the costs of production, rejection, inspection, depreciation, delivery, holding, and raw material purchases. For this, we categorize the fluctuation in two problems: (i) positive demand fluctuation $(\delta>0)$, and (ii) negative demand fluctuation $(\delta<0)$. For $\delta>0$, we consider both backorder and lost sales costs and, for $\delta<0$, the cost due to a decrease in demand, and determine revenue from the selling price.

(a) For $\delta>0$

Total production cost $=\frac{C_{p}}{r} \sum_{i=1}^{n} X_{i}$

Total rejection cost $=C_{R}\left(\frac{1}{r}-1\right) \sum_{i=1}^{n} X_{i}$

Total inspection cost $=\frac{C_{I} C_{p}}{r} \sum_{i=1}^{n} X_{i}$

Cost of interest and depreciation $=n a A^{-b} r^{c}$ 
Total raw material cost $=\sum_{i=1}^{n} C_{r} Z_{i}=\frac{N C_{r}}{r} \sum_{i=1}^{n} X_{i}$

Raw material holding cost $=\frac{1}{2 r} H_{1} N \sum_{i=1}^{n} X_{i}$

Total delivery cost $=\sum_{i=1}^{n} C_{d} Y_{i}$

Total ending inventory holding cost $=H_{2} \sum_{i=1}^{n} e_{i}$

Backorder cost $=B \sum_{i=1}^{n} i\left(X_{i}-A P_{i}\right)$

Lost sales cost $=L\left(\sum_{i=1}^{n} A P_{i}+\delta-\sum_{i=1}^{n} X_{i}\right)$

Total revenue $=S \sum_{i=1}^{n} X_{i}$

\section{Final mathematical model for $\delta>0$}

Total profit $=$ total revenue - total costs, is the objective function and to be maximized, which is obtained using equations (18) - (28) and subject to constraints (29) - (36).

$e_{i} \geq E_{i} ; \forall i$ [Constraint of ending inventory]

$b_{i} \geq B_{i} ; \forall i$ [Constraint of beginning inventory]

$X_{i} \leq r P ; \forall i$ [Production quantity must be less than or equal to maximum capacity]

$\sum_{i=1}^{n} X_{i} \leq \sum_{i=1}^{n} D_{i}+b_{n+1}-b_{1}+\delta$ [Limitation of total production quantity]

$\sum_{i=1}^{n} X_{i} \geq \sum_{i=1}^{n} A P_{i}$ [Limitation of total production]

$\sum_{i=1}^{n} Y_{i} \geq \sum_{i=1}^{n} R_{i}$ [Limitation of total delivery]

$\sum_{i=1}^{n} Y_{i} \leq \sum_{i=1}^{n} D_{i}+\delta$ [Limitation of total delivery]

$X_{i}, Y_{i}, Z_{i} \geq 0$ and integer; $\forall i$ [Non-negativity constraint]

\section{(b) For $\boldsymbol{\delta}<\mathbf{0}$}

Total production cost $=\frac{C_{p}}{r} \sum_{i=1}^{n} X_{i}$

Total rejection cost $=C_{R}\left(\frac{1}{r}-1\right) \sum_{i=1}^{n} X_{i}$

Total inspection cost $=\frac{C_{I} C_{p}}{r} \sum_{i=1}^{n} X_{i}$

Cost of interest and depreciation $=n a A^{-b} r^{c}$

Total raw material cost $=\sum_{i=1}^{n} C_{r} Z_{i}=\frac{N C_{r}}{r} \sum_{i=1}^{n} X_{i}$

Raw material holding cost $=\frac{1}{2 r} H_{1} N \sum_{i=1}^{n} X_{i}$

Total delivery cost $=\sum_{i=1}^{n} C_{d} Y_{i}$

Total ending inventory holding cost $=H_{2} \sum_{i=1}^{n} e_{i}$

Cost due to decrease in demand $=C_{L}\left(\sum_{i=1}^{n} A P_{i}-\sum_{i=1}^{n} X_{i}\right)$

Total revenue $=S \sum_{i=1}^{n} X_{i}$ 


\section{Final mathematical model for $\delta<0$}

Total profit $=$ total revenue - total costs, is the objective function and to be maximized, which is obtained using equations (37) - (46) and subject to constraints (47) - (52).

$e_{i} \geq E_{i} ; \forall i$ [Constraint of ending inventory]

$b_{i} \geq B_{i} ; \forall i$ [Constraint of beginning inventory]

$X_{i} \leq r P ; \forall i$ [Limitation of production quantity of each period]

$\sum_{i=1}^{n} X_{i}=\sum_{i=1}^{n} D_{i}+b_{n+1}-b_{1}-\delta$ [Limitation of total production quantity]

$Y_{i}=\sum_{i=1}^{n} R_{i}-\delta$ [Limitation of total delivery quantity]

$X_{i}, Y_{i}, Z_{i} \geq 0$ and integer; $\forall i$ [Non-negativity constraint]

\section{Solution approaches}

In this section, we develop solution approaches for both ideal and recovery plans, and propose some heuristics to generate a recovery plan after a sudden disturbance occurs in the systems.

\subsection{Solution approach for ideal plan}

As the model developed for the ideal plan belongs to a constrained mathematical program, we solve it using the SIMPLEX method. The SIMPLEX method is a popular search procedure to solve constrained mathematical programing problems. It shifts one solution at a time through the set of basic feasible solutions until optimal solution is found.

\subsection{Proposed heuristic for managing disturbance}

We develop a heuristic for managing each disturbance type, i.e., a demand fluctuation, or production and supply disruptions, as well as another for handling three types of disturbances in a period.

We propose a heuristic for managing a sudden demand fluctuation based on the approaches developed in the literature (Paul et al. 2018; Paul et al. 2014c). The steps in Heuristic 1 for a sudden demand fluctuation are as follows.

Step 1: Input data for ideal plan.

Step 2: Determine and record ideal plan.

Step 3: Determine spare capacity $\left(S C_{i}\right)$ of each period.

Step 4: Input demand fluctuation amount $(\delta)$.

Step 5: For $\delta>0$

$$
\begin{array}{r}
5.1 \text { For } 0 \leq \delta \leq S C_{1} \\
\text { If } B \leq L \text {, then }
\end{array}
$$




$$
\begin{aligned}
& X_{1}=A P_{1}+\delta \\
& X_{i}=A P_{i} ; i=2,3 \ldots n
\end{aligned}
$$

If $B>L$, then

5.2 For $k=2$ to $n$

$$
X_{i}=A P_{i} ; i=1,2,3 \ldots n
$$

$$
\begin{aligned}
& \text { For } \sum_{j=1}^{k-1} S C_{j}<\delta \leq \sum_{j=1}^{k} S C_{j} \\
& \text { If } B \leq \frac{L}{k} \text {, then } \\
& X_{i}=A P_{i}+S C_{i} ; i=1,2,3 \ldots k-1 \\
& X_{k}=A P_{k}+\delta-\sum_{j=1}^{k-1} S C_{j} \\
& X_{i}=A P_{i} ; i=k+1, k+2 \ldots n \\
& \text { If } \frac{L}{k}<B \leq \frac{L}{k-1} \text {, then } \\
& X_{i}=A P_{i}+S C_{i} ; i=1,2,3 \ldots k-1 \\
& X_{i}=A P_{i} ; i=k, k+1, k+2 \ldots n
\end{aligned}
$$

$$
\begin{aligned}
& \text { If } \frac{L}{2}<B \leq L, \text { then } \\
& \quad \begin{aligned}
X_{1} & =A P_{1}+S C_{1} \\
& X_{i}=A P_{i} ; i=2,3 \ldots n
\end{aligned}
\end{aligned}
$$

If $B>L$, then

5.3 For $\delta>\sum_{j=1}^{n} S C_{j}$

$$
X_{i}=A P_{i} ; i=1,2,3 \ldots n
$$

If $B \leq \frac{L}{n}$, then

$$
\begin{gathered}
X_{i}=A P_{i}+S C_{i} ; i=1,2,3 \ldots n \\
\text { If } \frac{L}{n}<B \leq \frac{L}{n-1}, \text { then } \\
X_{i}=A P_{i}+S C_{i} ; i=1,2,3 \ldots n-1 \\
X_{n}=A P_{n} \\
\ldots \ldots \ldots . . \\
\text { If } \frac{L}{2}<B \leq L, \text { then } \\
X_{1}=A P_{1}+S C_{1} \\
X_{i}=A P_{i} ; i=2,3 \ldots n
\end{gathered}
$$

If $B>L$, then

Step 6: For $\delta<0$

$$
X_{i}=A P_{i} ; i=1,2,3 \ldots n
$$

$$
\begin{aligned}
& X_{1}=A P_{1}-|\delta| \\
& X_{i}=A P_{i} ; i=2,3 \ldots n
\end{aligned}
$$

Step 7: Determine raw material required and final product delivery quantity.

$$
\begin{aligned}
& Y_{i}=B_{i}+X_{i}-E_{i} ; i=1,2,3 \ldots n \\
& Z_{i}=N * \frac{X_{i}}{r} ; i=1,2,3 \ldots n
\end{aligned}
$$

Step 8: Determine total profit and different costs.

Step 9: Stop.

In the proposed heuristic after a sudden demand fluctuation, the recovery plan is generated by negotiating between different costs. We first determine the ideal condition of supply chain plan by using Steps 1-3. Then after a sudden demand fluctuation in the system, the disturbance scenario is given input by using Step 4 . For positive demand fluctuation $(\delta>0)$, the recovery 
plan is determined by using Step 5. We determine the most favorable condition in the recovery plan by using Steps 5.1-5.3 to minimize total backorder and lost sales costs. For negative demand fluctuation $(\delta<0)$, the recovery plan is determined by using Step 6. Then Step 7 determines the raw material supply and final product delivery quantity. Total profit and different costs in the recovery plan are determined by using Step 8. Finally, Step 9 terminates the program.

Based on the similar concepts (Paul et al. 2018; Paul et al. 2014c), we also re-develop two different heuristics to generate a recovery plan after a sudden production and raw material supply disruption, respectively. Heuristic 2 and Heuristic 3 for generating a recovery plan for a sudden production disruption and raw material supply disruption are presented in Appendix C and Appendix D respectively. The heuristic for generating plan considering the combined effects of multiple disturbances is presented in Appendix E.

\section{Simulation approach}

We develop a simulation approach to bring the supply chain disturbance problem nearer to a real-life process. We use six steps to develop the simulation approach as follows.

Step 1: Generate a random number for disturbance type (1-4).

Step 2: Generate random data for each disturbance type.

2.1 if disturbance type $=1$, generate a random number for amount of demand fluctuation $(\delta)$ using normal distribution with mean 500 and standard deviation 250.

2.2 if disturbance type $=2$, generate random number for disruption start time $\left(t_{s}\right)$ using Uniform distribution and disruption duration $\left(T_{d p}\right)$ through Exponential distribution between 0 and 1 and 0.00001 and $1-t_{s}$ respectively.

2.3 if disturbance type $=3$, generate a random number for supply disruption duration $\left(T_{d s}\right)$ using Poisson distribution between 0.00001 and 1.

2.4 if disturbance type $=4$, generate random number for disturbance scenario of each disturbance type for multiple disturbances in a period.

\section{Step 3:}

3.1 if disturbance type $=1$, then run Heuristic 1 .

3.2 if disturbance type $=2$, then run Heuristic 2 .

3.3 if disturbance type $=3$, then run Heuristic 3 .

3.4 if disturbance type $=4$, then run Heuristic 4 .

Step 4: Repeat steps 1-3 for 4000 times.

Step 5: Record and analyze results. 
Step 6: Stop.

\section{Analyses of results}

In this section, we analyze the results for both the ideal supply chain and recovery plans.

\subsection{Ideal plan}

The following data are considered for the ideal supply chain system.

$n=12, P=1200, B_{1}=300, B_{n+1}=200, N=2, A=50, C_{p}=2, C_{d}=0.5, C_{r}=1.5$,

$H_{1}=0.5, H_{2}=0.5, S=20, r=0.98, C_{I}=0.02, C_{R}=4, a=1000, b=0.5, c=0.75$,

$D_{i}=\left[\begin{array}{lll}1000120015001100100080090012001300120015001000\end{array}\right]$

We use the SIMPLEX method to solve the mathematical model developed in Section 4.1 to obtain the ideal plan for the next 12 periods, which is presented in Table 3.

Table 3: Ideal plan

\begin{tabular}{|c|c|c|c|c|c|c|c|c|c|c|c|c|}
\hline \multirow{2}{*}{ Parameter } & \multicolumn{10}{|c|}{ Period } \\
\cline { 2 - 15 } & 1 & 2 & 3 & 4 & 5 & 6 & 7 & 8 & 9 & 10 & 11 & 12 \\
\hline$D_{i}$ & 1000 & 1200 & 1500 & 1100 & 1000 & 800 & 900 & 1200 & 1300 & 1200 & 1500 & 1000 \\
\hline$A P_{i}$ & 1048 & 1176 & 1176 & 1100 & 1000 & 1044 & 1176 & 1176 & 1176 & 1176 & 1176 & 1176 \\
\hline$B_{i}$ & 300 & 348 & 324 & 0 & 0 & 0 & 244 & 520 & 496 & 372 & 348 & 24 \\
\hline$E_{i}$ & 348 & 324 & 0 & 0 & 0 & 244 & 520 & 496 & 372 & 348 & 24 & 200 \\
\hline$R_{i}$ & 1000 & 1200 & 1500 & 1100 & 1000 & 800 & 900 & 1200 & 1300 & 1200 & 1500 & 1000 \\
\hline$R M_{i}$ & 2139 & 2400 & 2400 & 2245 & 2041 & 2131 & 2400 & 2400 & 2400 & 2400 & 2400 & 2400 \\
\hline
\end{tabular}

\subsection{Recovery plan}

To generate the recovery plan, we additionally consider the following cost data.

$$
B=3, L=15 \text {, and } C_{L}=10
$$

We generate random data using Uniform distribution for different disturbance parameters to compare the severity of each disturbance type. We also perform random experiment to analyse the results. For demand fluctuation, we generate random data using normal distribution. For production disruption, we generate random data for disruption duration using Uniform distribution and for supply disruption duration, we use Poisson distribution. However, any other distribution can be used for generating random data.

\subsubsection{Recovery plan for a sudden demand fluctuation}

In the event of a sudden demand fluctuation, the recovery plan is generated using its proposed heuristic. A sample result, for $\delta=500$, is presented in the recovery plan in Table 4. 
Table 4: Recovery plan after demand fluctuation

\begin{tabular}{|c|c|c|c|c|c|c|c|c|c|c|c|c|}
\hline \multirow{2}{*}{ Parameter } & \multicolumn{10}{|c|}{ Period } \\
\cline { 2 - 13 } & 1 & 2 & 3 & 4 & 5 & 6 & 7 & 8 & 9 & 10 & 11 & 12 \\
\hline$X_{i}$ & 1176 & 1176 & 1176 & 1176 & 1176 & 1164 & 1176 & 1176 & 1176 & 1176 & 1176 & 1176 \\
\hline$Y_{i}$ & 1128 & 1200 & 1500 & 1176 & 1176 & 920 & 900 & 1200 & 1300 & 1200 & 1500 & 1000 \\
\hline$Z_{i}$ & 2400 & 2400 & 2400 & 2400 & 2400 & 2376 & 2400 & 2400 & 2400 & 2400 & 2400 & 2400 \\
\hline
\end{tabular}

Total profit $=184.84$ thousand; total backorder cost $=6.096$ thousand; and total lost sales cost $=0$

\subsubsection{Recovery plan for a sudden production disruption}

In the event of a sudden production disruption, we generate the recovery plan using its proposed heuristic. A sample result, for $t_{s}=0.1$ and $T_{d p}=0.5$, is presented in the recovery plan in Table 5 .

Table 5: Recovery plan after production disruption

\begin{tabular}{|c|c|c|c|c|c|c|c|c|c|c|c|c|}
\hline \multirow{2}{*}{ Parameter } & \multicolumn{10}{|c|}{ Period } \\
\cline { 2 - 13 } & 1 & 2 & 3 & 4 & 5 & 6 & 7 & 8 & 9 & 10 & 11 & 12 \\
\hline$X_{i}$ & 588 & 1176 & 1176 & 1176 & 1176 & 1176 & 1176 & 1176 & 1176 & 1176 & 1176 & 1176 \\
\hline$Y_{i}$ & 540 & 1200 & 1500 & 1176 & 1176 & 932 & 900 & 1200 & 1300 & 1200 & 1500 & 1000 \\
\hline$Z_{i}$ & 2139 & 1461 & 2400 & 2400 & 2400 & 2400 & 2400 & 2400 & 2400 & 2400 & 2400 & 2400 \\
\hline
\end{tabular}

\subsubsection{Recovery plan for a sudden supply disruption}

In the event of a sudden supply disruption, we use its proposed heuristic to generate the recovery plan. A sample result, for $T_{d s}=0.6$, is presented in the recovery plan in Table 6 .

Table 6: Recovery plan after supply disruption

\begin{tabular}{|c|c|c|c|c|c|c|c|c|c|c|c|c|}
\hline \multirow{2}{*}{ Parameter } & \multicolumn{10}{|c|}{ Period } \\
\cline { 2 - 13 } & 1 & 2 & 3 & 4 & 5 & 6 & 7 & 8 & 9 & 10 & 11 & 12 \\
\hline$X_{i}$ & 470 & 1176 & 1176 & 1176 & 1176 & 1176 & 1176 & 1176 & 1176 & 1176 & 1176 & 1176 \\
\hline$Y_{i}$ & 422 & 1200 & 1500 & 1176 & 1176 & 932 & 900 & 1200 & 1300 & 1200 & 1500 & 1000 \\
\hline$Z_{i}$ & 2139 & 1221 & 2400 & 2400 & 2400 & 2400 & 2400 & 2400 & 2400 & 2400 & 2400 & 2400 \\
\hline \multicolumn{11}{|c|}{ Total profit $=173.70$ thousand; total backorder cost $=4.776$ thousand; and total lost sales } \\
cost $=2.904$ thousand \\
\hline
\end{tabular}

\subsection{Comparison of heuristic results}

To validate the heuristics developed for managing demand fluctuation and disruptions to production and supply, we generate 300 random test instances (100 for each disturbance type) by varying the backorder and lost sales cost data and disturbance parameters. Then we compare 
the results obtained from both the heuristics and SIMPLEX method for 300 random test instances. To this aim, we determine the average percentage of deviation of solutions by using Equation (53), which is commonly used in the literature (Paul et al., 2014c; 2015, 2018). The test instances are generated from a Uniform random distribution by varying disturbance data. In this comparison experiment, the average percentage of deviation between the solutions obtained from the heuristics and SIMPLEX, calculated by using Equation (53), is almost $0.00 \%$. It can be said that the heuristics are capable of producing accurate and consistent solutions. The average percentage of deviation

$=\frac{1}{M} \sum \frac{\mid \text { Total profit from heuristc-Total profit from SIMPLEX } \mid}{\text { Total profit from SIMPLEX }} \times 100 \%$

Here, $M$ represents the number of random test problems.

\subsection{Severity of each disturbance type}

To compare the severity of each disturbance type, we generate 500 more test problems for each disturbance using a Uniform probability distribution and solve them using the proposed corresponding heuristic. We determine the means and standard deviations of total profit from the results, as presented in Table 7 . We consider the following data range of disturbance parameters.

(a) Demand fluctuation amount $=\left[0, \sum_{\forall i} S C_{i}\right]$

(b) Supply disruption duration $=[0.0001,1]$

(c) Production disruption duration $=\left[0.0001,1-t_{s}\right]$

Table 7: Total profit for each disturbance type

\begin{tabular}{|c|c|c|}
\hline \multirow{2}{*}{ Disturbance type } & \multicolumn{2}{|c|}{ Total profit (thousands) } \\
\cline { 2 - 3 } & Mean & Standard deviation \\
\hline Demand fluctuation & 185.19 & 0.3533 \\
\hline Production disruption & 178.08 & 5.3127 \\
\hline Supply disruption & 175.37 & 7.2898 \\
\hline
\end{tabular}

As can be seen, the mean total profit reduces significantly in the case of a supply disruption because the effect of this disturbance starts at the beginning of a period and may continue until the end of a period. Therefore, it can be said that its effect is more severe than those of the other two disturbances. 


\subsection{Experimentation using random data}

We generate 500 random test scenarios for each type of disturbance by varying the value of disturbance parameters and solve them using the appropriate heuristic. We analyze the total profit pattern for the disturbance over the 500 random scenarios, and changes in the costs and total profit with the amount of disturbance.

\subsubsection{Experimentation for demand fluctuation}

We generate 500 random data scenarios for demand fluctuations using a normal distribution with mean $=500$ and standard deviation $=250$, and present the total profit pattern in Figure 2 . We determine that the mean and standard deviation of total profit as 190.70 and 1.23 thousand respectively. We also determine the minimum and maximum values of the total profit as 183.54 and 191.60 thousand respectively.

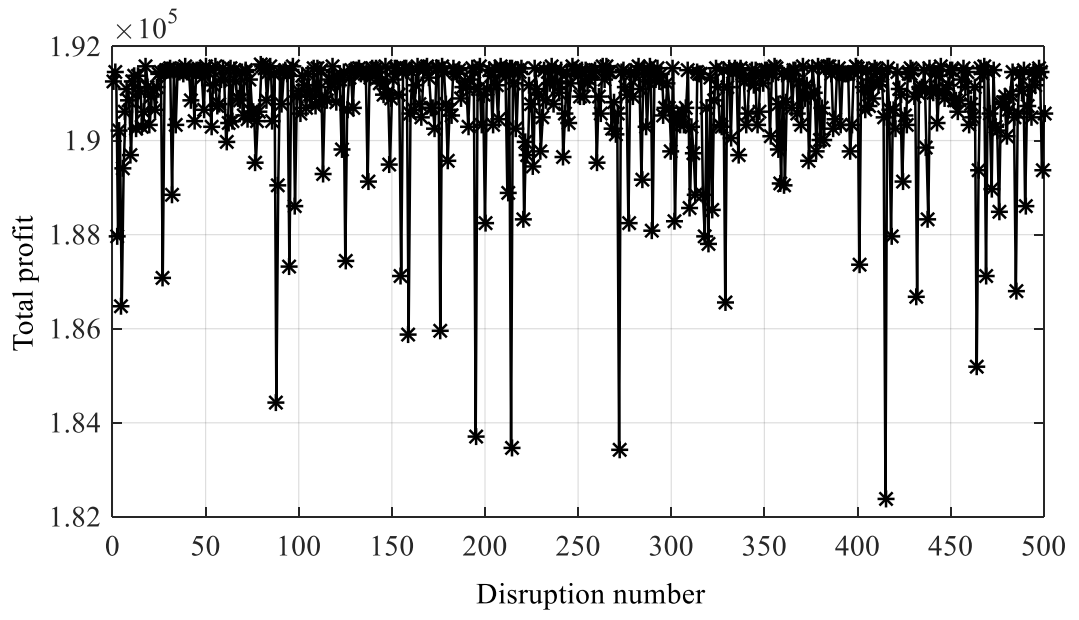

Figure 2: Total profit vs. random demand fluctuation

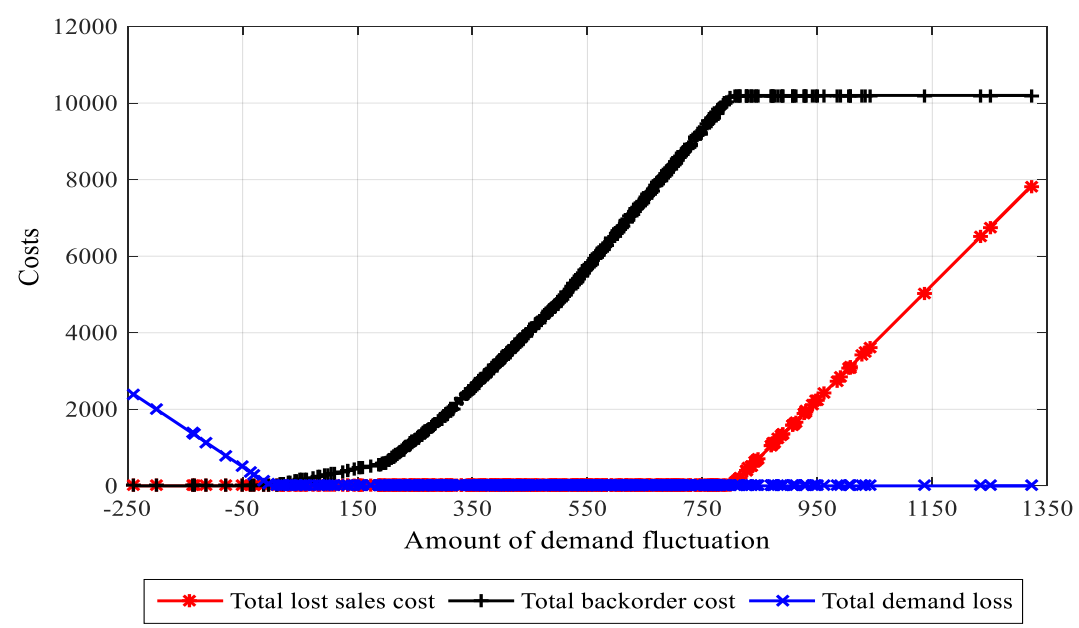

Figure 3: Different costs vs. amount of demand fluctuation 
Figure 3 presents the variations in different costs with the amount of demand fluctuation. We obeserve that the cost due to loss of demand exists only when the fluctuation amount is negative but there are no backorder or lost sales. However, when the fluctuation amount is positive, both backorder and lost sales are present in the recovery plan. The backorder cost increases with fluctuation amounts up to 797 when there are no lost sales because the recovery plan is capable of fulfilling the demand using only backorder. Then, lost sales cost is introduced into the recovery plan and the backorder cost becomes a fixed amount so that both backorder and lost sales are present. The variations in total profit with demand fluctuation amounts are presented in Figure 4. For a negative fluctuation, the total profit decreases with the fluctuation amount however, for a positive fluctuation, it is greater than that in the ideal plan when the fluctuation amount is up to 797 , because the revenue earned is greater than the cost incurred due to the increase in demand. Then, the total profit decreases with the fluctuation amount, this is because the lost sales cost introduced into the recovery plan.

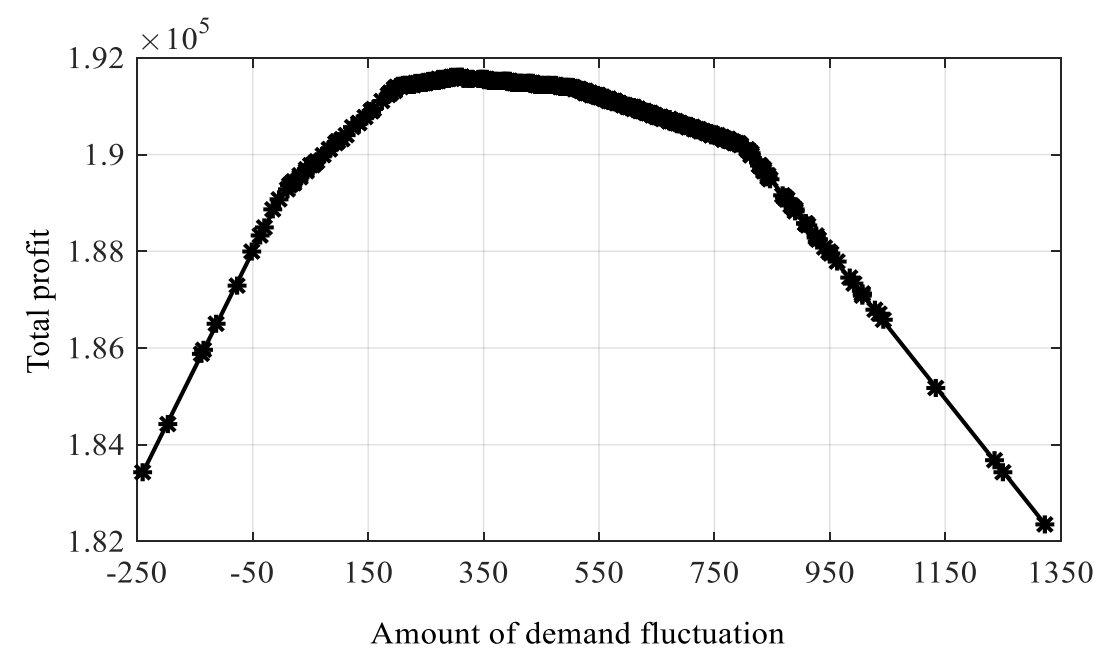

Figure 4: Total profit vs. amount of demand fluctuation

\subsubsection{Experimentation for production disruption}

We generate 500 random test scenarios for a production disruption using a Uniform distribution within the range of $(0,1)$ for $t_{s}$ and an Exponential distribution within the range of $(0.0001$, $1-t_{s}$ ) for $T_{d p}$. The total profit pattern for these random production disruption occurrences is presented in Figure 5. We determine that the mean and standard deviation of total profit are 187.35 and 2.76 thousand respectively. The minimum and maximum values of total profit are calculated as 173.10 and 189.20 thousand respectively.

Figure 6 presents the changes in different costs with the duration of the production disruption. We observe that there are no backorder or lost sales costs when the disruption duration is less 
than 0.17 . Then, the backorder cost is introduced into the system and increases with disruption durations up to 0.67 because the recovery plan is capable of satisfying the production loss using only backorder. After a disruption duration of 0.67 , the lost sales cost is included in the recovery plan, and the backorder cost becomes a fixed amount, so that both backorder and lost sales costs are present.

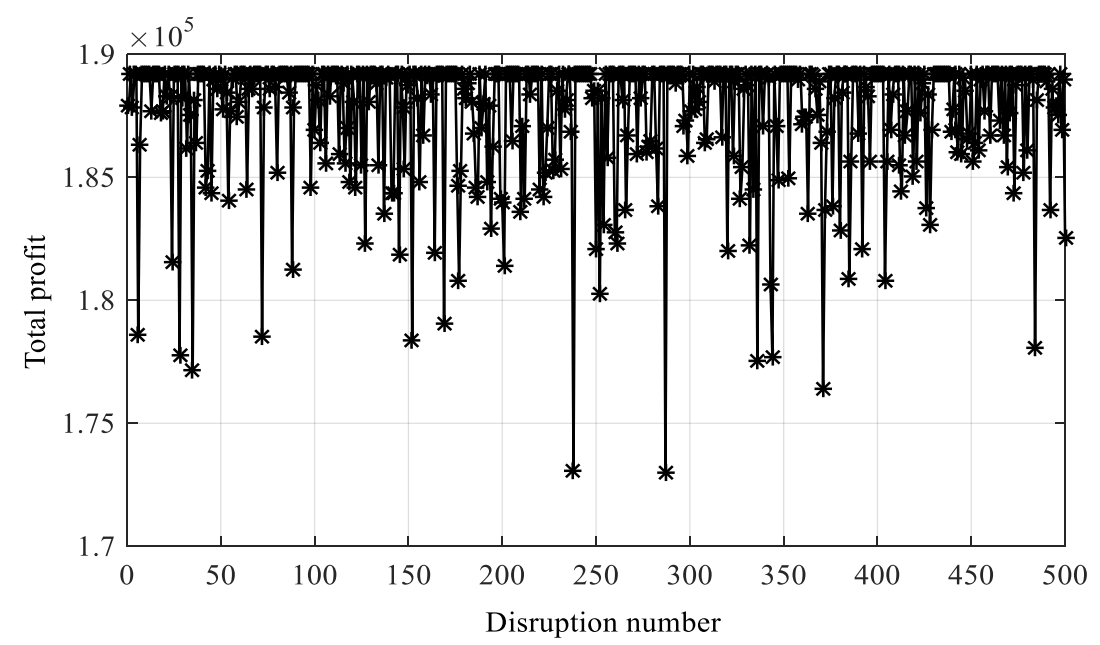

Figure 5: Total profit vs. random production disruption

The variations in total profit with the duration of a production disruption are presented in Figure 7. The total profit does not change when the disruption duration is smaller than 0.17 because no backorder or lost sales costs are present and the recovery plan is capable of compensating for the production loss in its first period. Then, the total profit decreases slowly with disruption durations up to 0.67 because only backorder are present. Following a disruption duration of 0.67, total profit decreases at a greater rate, this is because of the lost sales cost being incorporated in the recovery plan.

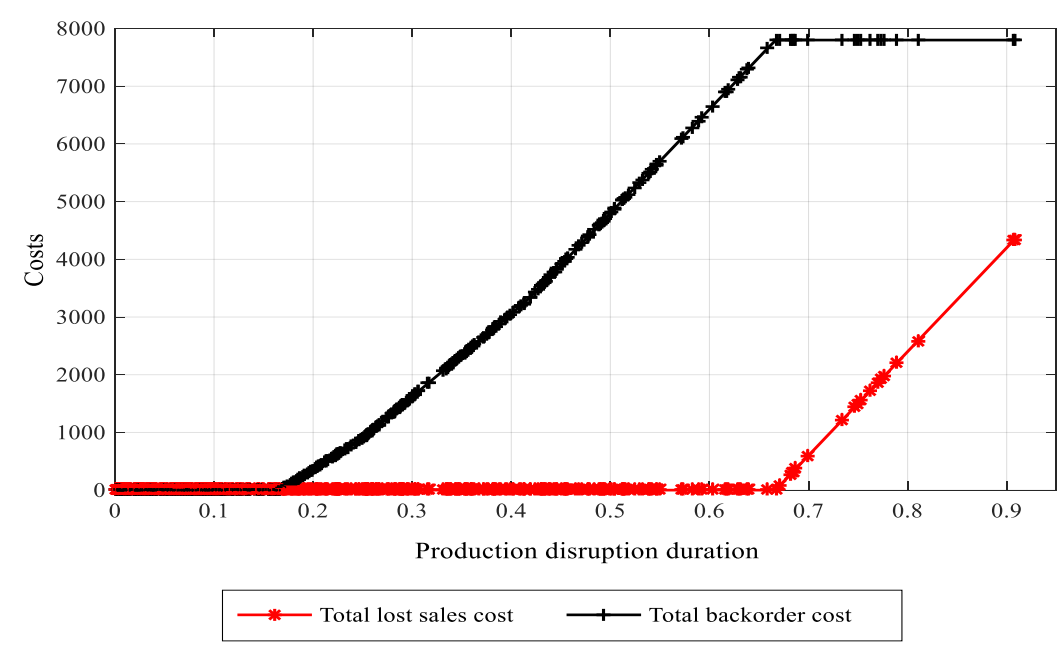

Figure 6: Different costs vs. duration of production disruption 


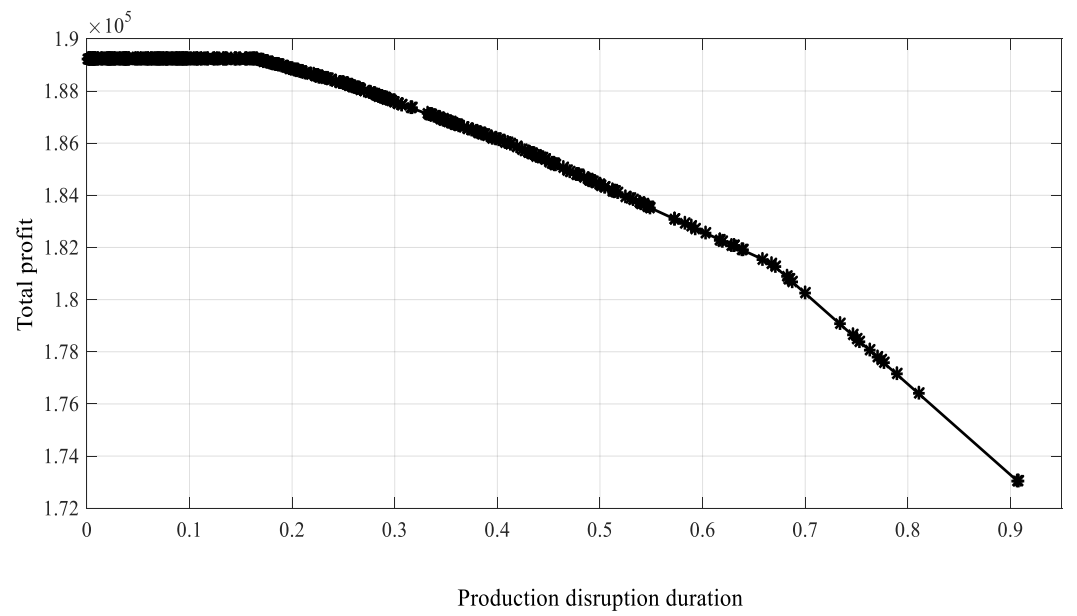

Figure 7: Total profit vs. duration of production disruption

\subsubsection{Experimentation for raw material supply disruption}

We generate 500 test problems randomly for a supply disruption duration using a Poisson distribution. We use the range of the duration as $(0.0001,1)$, and from the experiment, the total profit pattern is illustrated in Figure 8. We determine that the mean and standard deviation of total profit are 184.76 and 5.15 thousand respectively. We also calculate the minimum and maximum values of the total profit as 170.06 and 189.20 thousand respectively. Figures 9 and 10 present the variations in different costs and total profit respectively for different supply disruption durations, which are similar to those in Figures 6 and 7.

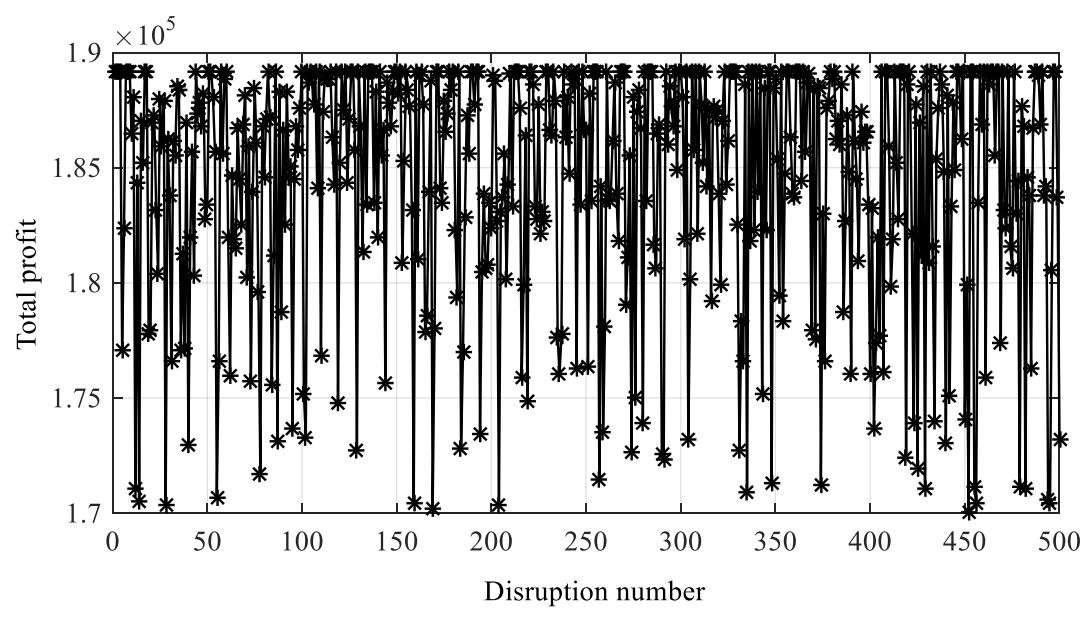

Figure 8: Total profit vs. random supply disruption 


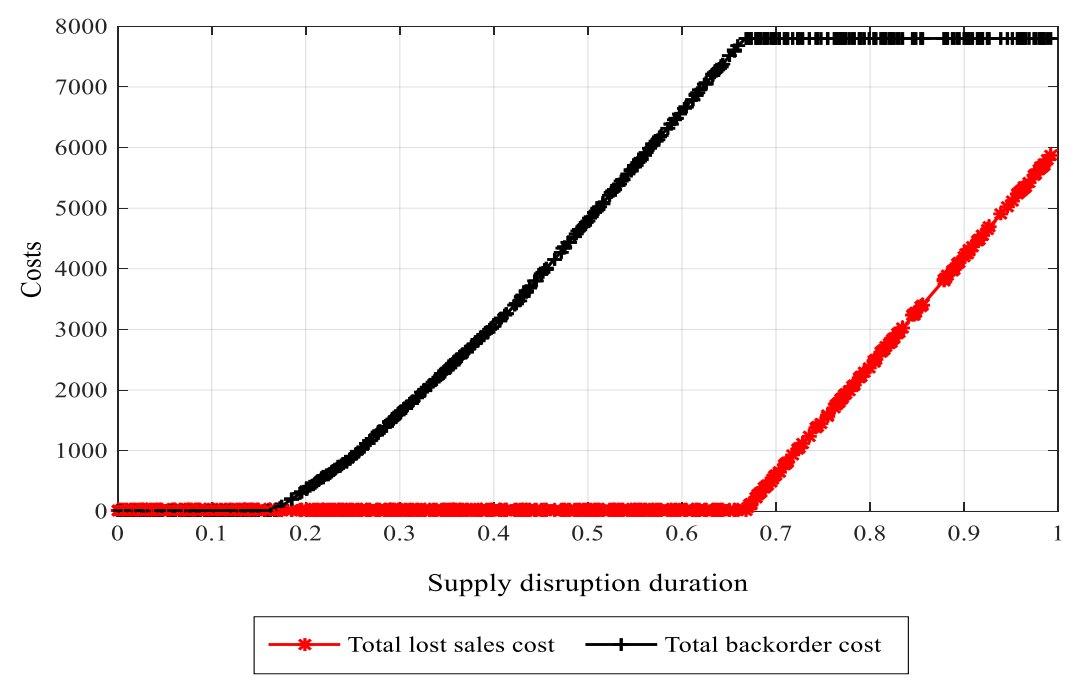

Figure 9: Different costs vs. duration of supply disruption

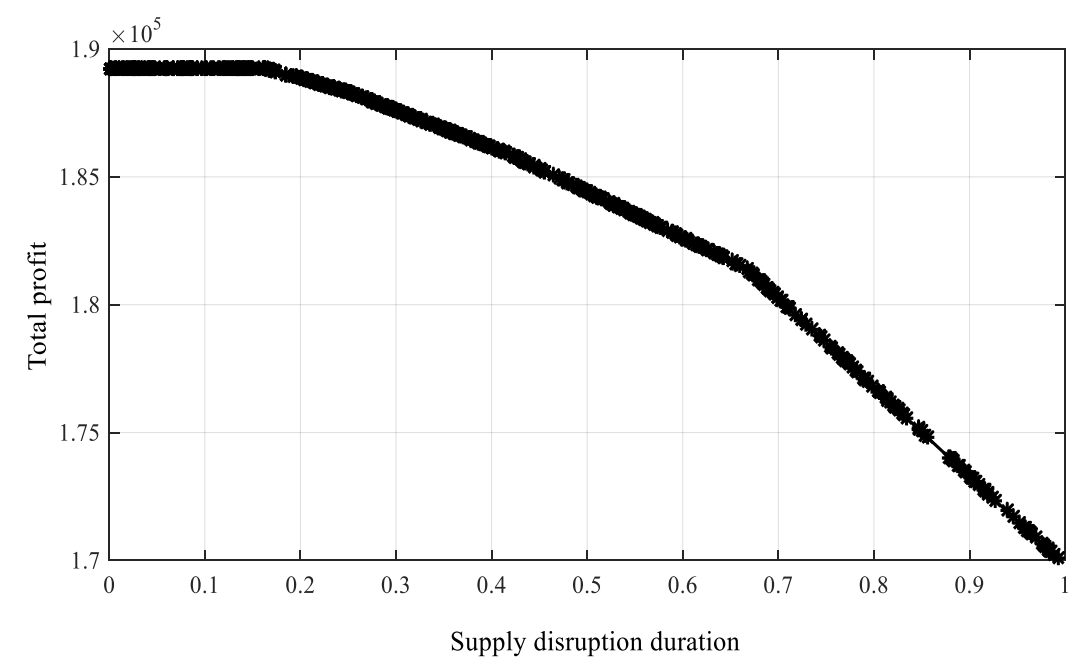

Figure 10: Total profit vs. duration of supply disruption

\subsubsection{Experimentation for multiple disturbances}

We generate 500 random scenarios for multiple disturbances in a period and solve them using the proposed heuristic, which considers the combined effects of multiple disturbances. The results are presented in Figure 11, in which it can be observed that total profit varies significantly and that the mean total profit reduces greatly with mean and standard deviation of 175.26 and 8.79 thousand respectively, and the minimum and maximum values as 154.11 and 191.02 thousand respectively. We have observed that the total profit decreases significantly in presence of multiple types of disturbances in supply chain. 


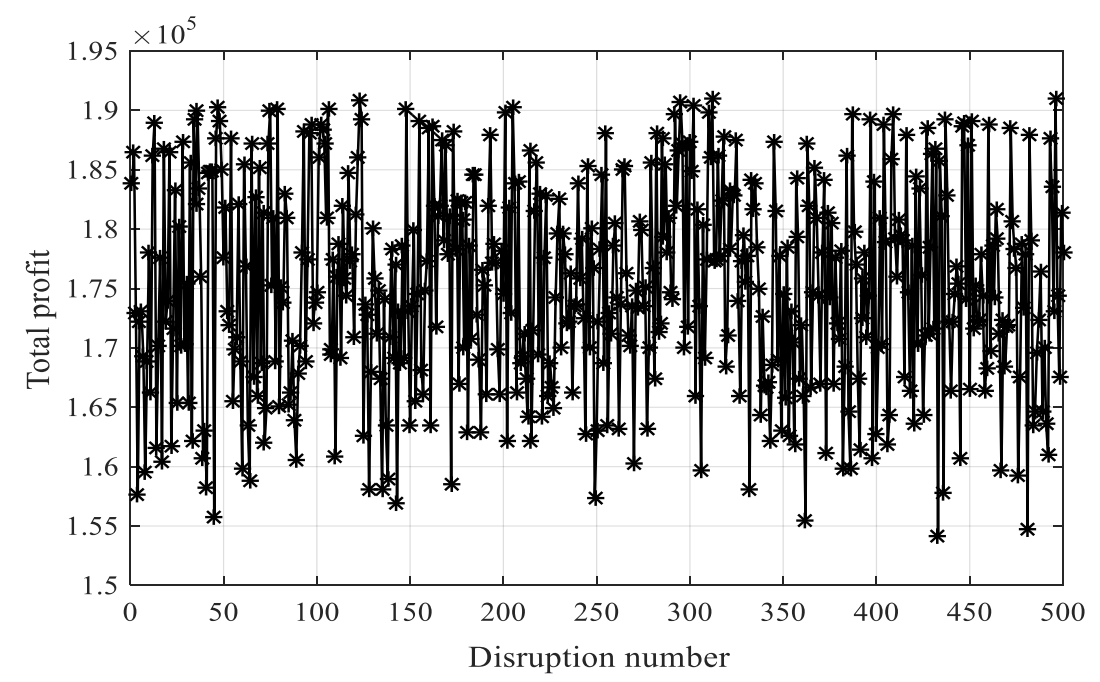

Figure 11: Total profit vs. random multiple disturbances

\subsection{Simulation results}

We run the simulation approach developed in Section 6 for 4000 random test problems, to make the supply chain disturbance problem close to a real-world process. The total profit pattern for this experiment is presented in Figure 12. We calculate the mean and standard deviation of total profit as 184.55 and 7.81 thousand respectively. We also determine the minimum and maximum values of the total profit as 152.27 and 191.60 thousand respectively.

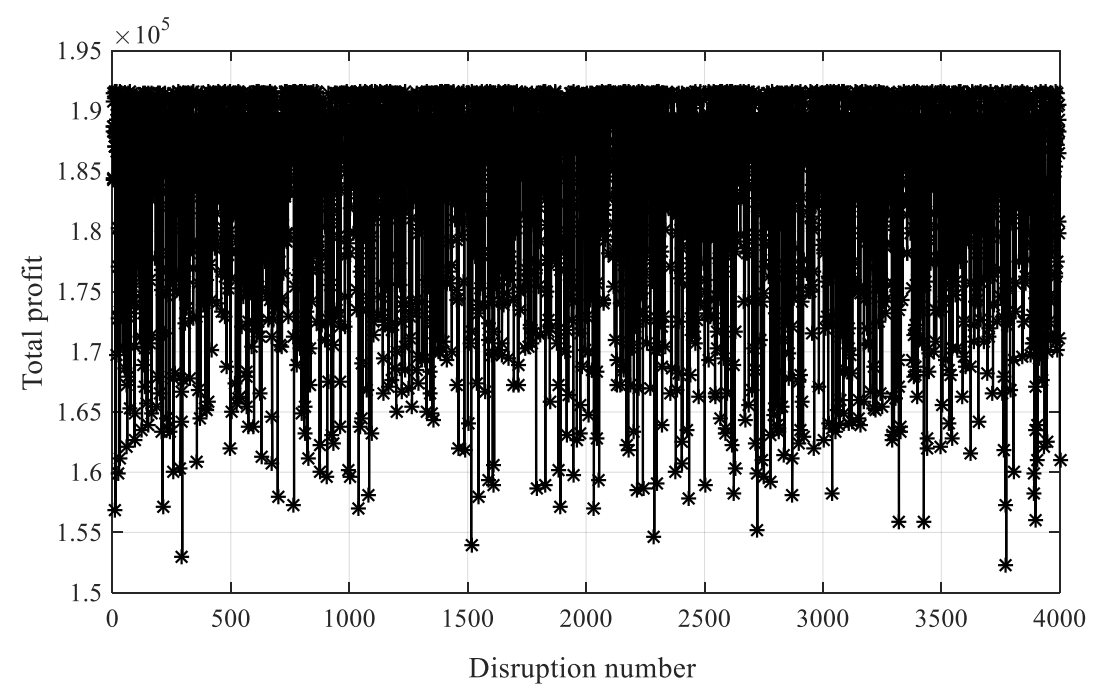

Figure 12: Total profit vs. occurrences of random disturbance from simulation run

From the experimentation and simulation, we have observed that our approaches are capable to handle all types of disturbance problems in a three-tier coordinated supply chain setting. Results also revealed that the recovery costs (summation of backorder and lost sales cost) can be significantly reduced by implementing the developed approaches. Figures 3, 6 and 9 provided insight about the condition of the presence of recovery cost and which recovery cost are more favorable and when. Figures 4, 7 and 10 provided the pattern of changes of total profit with 
amount of demand fluctuation, duration of production and supply disruption respectively. The experimentation and simulation for a significant number of randomly generated test problems proved the capability of the developed approaches to handle both separate and combined effects of disturbances and the results are summarized in Figures 2, 5, 8, 11 and 12. In summary, our developed approaches contribute to generating recovery plan to manage multiple types of supply chain disturbances by considering separate and combined effects.

\section{Conclusions}

The objective of this study was to develop sudden disturbance recovery models in a manufacturing supply chain system under imperfect production environment, considering sudden demand fluctuations and disruptions to production and raw material supply. A mathematical model was developed first for each disturbance type for managing sudden disturbances on a real-time basis. Due to expensive commercial optimization software and the complexity and computational intensity of the optimal solution, four heuristics were developed to solve the model for all possible types of sudden disturbances. The heuristics were capable of generating a recovery plan for a finite future period after the occurrence of a disturbance. We validated the heuristics results by comparing the solutions from the SIMPLEX method, which demonstrated that the average deviation of the total profit was $0.00 \%$ for 300 random test instances. A random experimentation was conducted to analyze the results and insight properties of developed quantitative models and, finally, a simulation approach was developed to make the developed approaches applicable to a real-life process. We also found that the heuristics were capable of producing consistent, quality results for all types of disturbances. The test results reveal that our proposed heuristics performed very well and were capable of efficiently dealing with large scale disruption problems while producing high quality results. So it can be said that the proposed approaches offer a powerful decision making tool for determining the recovery plan after the occurrence of sudden disturbances.

Compared with previous studies in the supply chain disturbance literature, this research is one of the first efforts to investigate recovery planning in the presence of both single and multiple types of sudden disturbances. However, there are several practical aspects that could be introduced into the developed approach to make the problem more comprehensive. It would be interesting extension to consider multiple entities (multiple suppliers, manufacturers and retailers) in each stage, and to analyze the consequence of different types of sudden disturbances 
on different stages of supply chain. It would be also interesting to extend the developed approaches for multiple types of items. In addition, considering safety-stock level and different shipment policies (multiple lot-for-lot, equal-sized shipment policies, and geometric shipment policies) in the recovery plan, and analyzing the effect of different types of sudden disturbances on them would be another interesting future research direction.

\section{References}

Adhitya, A., Srinivasan, R., \& Karimi, I. A. (2007). Amodel-based rescheduling framework formanaging abnormal supply chain events. Comput. Chem. Eng., 31, 496-518.

Ambulkar, S., Blackhurst, J., \& Grawe, S. (2015). Firm's resilience to supply chain disruptions: Scale development and empirical examination. Journal of Operations Management, 33, 111-122.

Atoei, F. B., Teimory, E., \& Amiri, A. B. (2013). Designing reliable supply chain network with disruption risk. International Journal of Industrial Engineering Computations, 4(1), 111126.

Bandaly, D., Satir, A., \& Shanker, L. (2016). Impact of lead time variability in supply chain risk management. International Journal of Production Economics, 180, 88-100.

Blome, C., \& Schoenherr, T. (2011). Supply chain risk management in financial crises-a multiple case-study approach. International Journal of Production Economics, 134(1), 43-57.

Bradley, J. R. (2014). An improved method for managing catastrophic supply chain disruptions. Business Horizons, 57(4), 483-495.

Burke, G. J., Carrillo, J. E., \& Vakharia, A. J. (2007). Single versus multiple supplier sourcing strategies. European Journal of Operational Research, 182(1), 95-112.

Chaudhuri, A., Mohanty, B. K., \& Singh, K. N. (2013). Supply chain risk assessment during new product development: a group decision making approach using numeric and linguistic data. International Journal of Production Research, 51(10), 2790-2804. doi:10.1080/00207543.2012.654922

Chen, J., Sohal, A. S., \& Prajogo, D. I. (2013). Supply chain operational risk mitigation: a collaborative approach. International Journal of Production Research, 51(7), 2186-2199.

Cheng, T. C. E. (1989). An economic production quantity model with flexibility and reliability considerations. European Journal of Operational Research, 39(2), 174-179.

Chopra, S., \& Meindl, P. (2007). Supply chain management. Strategy, planning \& operation. Springer.

Chopra, S., \& Sodhi, M. S. (2004). Managing Risk To Avoid Supply-Chain Breakdown. MIT Sloan Management Review, 46(1), 53-61.

Chowdhury, P., Lau, K. H., \& Pittayachawan, S. (2016). Supply risk mitigation of small and medium enterprises: a social capital approach. In Proc. of 21st International Symposium on Logistics (pp. 37-44). Centre for Concurrent Enterprise, Nottingham University.

Christopher, M., Mena, C., Khan, O., \& Yurt, O. (2011). Approaches to managing global sourcing risk. Supply Chain Management: An International Journal, 16(2), 67-81. doi:doi:10.1108/13598541111115338

Christopher, M., \& Peck, H. (2004). Building the resilient supply chain. The International Journal of Logistics Management, 15(2), 1-14.

Craighead, C. W., Blackhurst, J., Rungtusanatham, M. J., \& Handfield, R. B. (2007). The Severity of Supply Chain Disruptions: Design Characteristics and Mitigation Capabilities. 
Decision Sciences, 38(1), 131-156.

Das, A., Narasimhan, R., \& Talluri, S. (2006). Supplier integration-finding an optimal configuration. Journal of Operations Management, 24(5), 563-582.

DuHadway, S., Carnovale, S., \& Hazen, B. (2017). Understanding risk management for intentional supply chain disruptions: risk detection, risk mitigation, and risk recovery. Annals of Operations Research, (in press), 1-20. doi:10.1007/s10479-017-2452-0

Eisenstein, D. D. (2005). Recovering Cyclic Schedules Using Dynamic Produce-Up-To Policies. Operations Research, 53(4), 675-688.

Fahimnia, B., Tang, C. S., Davarzani, H., \& Sarkis, J. (2015). Quantitative models for managing supply chain risks: a review. European Journal of Operational Research, 247(1), 1-15.

Fang, J., Zhao, L., Fransoo, J. C., \& Van Woensel, T. (2013). Sourcing strategies in supply risk management: An approximate dynamic programming approach. Computers \& Operations Research, 40(5), 1371-1382.

Gupta, V., He, B., \& Sethi, S. P. (2015). Contingent sourcing under supply disruption and competition. International Journal of Production Research, 53(10), 3006-3027. doi:10.1080/00207543.2014.965351

Handfield, R., \& McCormack, K. P. (2007). Supply chain risk management: minimizing disruptions in global sourcing. Boca Raton, FL: Auberbach Publications.

Hasan, M. M., Shohag, M. A. S., Azeem, A., \& Paul, S. K. (2015). Multiple criteria supplier selection: A fuzzy approach. International Journal of Logistics Systems and Management, 20(4), 429-446. doi:10.1504/IJLSM.2015.068488

Hendricks, K. B., \& Singhal, V. R. (2003). The effect of supply chain glitches on shareholder wealth. Journal of Operations Management, 21(5), 501-522.

Hendricks, K. B., \& Singhal, V. R. (2005). An empirical analysis of the effect of supply chain disruptions on long-run stock price performance and equity risk of the firm. Production and Operations management, 14(1), 35-52.

Hishamuddin, H., Sarker, R., \& Essam, D. (2012). A disruption recovery model for a single stage production-inventory system. European Journal of Operational Research, 222(3), 464-473.

Ho, W., Dey, P. K., \& Lockstrom, M. (2011). Strategic sourcing: a combined QFD and AHP approach in manufacturing. Supply Chain Management: An International Journal, 16(6), 446-461.

Ho, W., Zheng, T., Yildiz, H., \& Talluri, S. (2015). Supply chain risk management: a literature review. International Journal of Production Research, 53(16), 5031-5069.

Huo, B., Qi, Y., Wang, Z., \& Zhao, X. (2014). The impact of supply chain integration on firm performance: The moderating role of competitive strategy. Supply Chain Management: An International Journal, 19(4), 369-384.

Ivanov, D., Dolgui, A., \& Sokolov, B. (2017). Literature review on disruption recovery in the supply chain. International Journal of Production Research, 55(20), 6158-6174.

Ivanov, D., Pavlov, A., Dolgui, A., Pavlov, D., \& Sokolov, B. (2016). Disruption-driven supply chain (re)-planning and performance impact assessment with consideration of pro-active and recovery policies. Transportation Research Part E: Logistics and Transportation Review, 90, 7-24.

Ivanov, D., Pavlov, A., \& Sokolov, B. (2014). Optimal distribution (re)planning in a centralized multi-stage supply network under conditions of the ripple effect and structure dynamics. European Journal of Operational Research, 237(2), 758-770.

Kim, Y., Chen, Y. S., \& Linderman, K. (2015). Supply network disruption and resilience: a network structural perspective. Journal of Operations Management, 33, 43-59.

Lockamy III, A., \& McCormack, K. (2010). Analysing risks in supply networks to facilitate outsourcing decisions. International Journal of Production Research, 48(2), 593-611. 
doi:10.1080/00207540903175152

Manuj, I., \& Mentzer, J. T. (2008). Global supply chain risk management. Journal of Business Logistics, 29(1), 133-155.

Mishra, D., Sharma, R. R. K., Kumar, S., \& Dubey, R. (2016). Bridging and buffering: Strategies for mitigating supply risk and improving supply chain performance. International Journal of Production Economics, 180, 183-197. doi:10.1016/J.IJPE.2016.08.005

Nagurney, A., Cruz, J., Dong, J., \& Zhang, D. (2005). Supply chain networks, electronic commerce, and supply side and demand side risk. European Journal of Operational Research, 164(1), 120-142. doi:10.1016/j.ejor.2003.11.007

Narasimhan, R., \& Talluri, S. (2009). Perspectives on risk management in supply chains. Journal of Operations Management, 27(2), 114-118.

Oke, A., \& Gopalakrishnan, M. (2009). Managing disruptions in supply chains: A case study of a retail supply chain. International Journal of Production Economics, 118(1), 168-174.

Paul, S. K., Asian, S., Goh, M., \& Torabi, S. A. (2019). Managing sudden transportation disruptions in supply chains under delivery delay and quantity loss. Annals of Operations Research, 273(1-2), 783-814.

Paul, S. K., Azeem, A., Sarker, R., \& Essam, D. (2014). Development of a production inventory model with uncertainty and reliability considerations. Optimization and Engineering, 15(3), 697-720.

Paul, S. K., Sarker, R., \& Essam, D. (2013). A Disruption Recovery Model in a ProductionInventory System with Demand Uncertainty and Process Reliability. Lecture Notes in Computer Science, 8104, 511-522.

Paul, S. K., Sarker, R., \& Essam, D. (2014a). Managing supply disruption in a three-tier supply chain with multiple suppliers and retailers. In IEEE International Conference on Industrial Engineering and Engineering Management (pp. 194-198).

Paul, S. K., Sarker, R., \& Essam, D. (2014b). Real time disruption management for a two-stage batch production-inventory system with reliability considerations. European Journal of Operational Research, 237(1), 113-128.

Paul, S. K., Sarker, R., \& Essam, D. (2014c). Managing real-time demand fluctuation under a supplier-retailer coordinated system. International Journal of Production Economics, 158, 231-243.

Paul, S. K., Sarker, R., \& Essam, D. (2015). Managing disruption in an imperfect productioninventory system. Computers \& Industrial Engineering, 84, 101-112.

Paul, S. K., Sarker, R., \& Essam, D. (2015). A disruption recovery plan in a three-stage production-inventory system. Computers and Operations Research, 57, 60-72.

Paul, S. K., Sarker, R., \& Essam, D. (2016). Managing risk and disruption in productioninventory and supply chain systems: a review. Journal of Industrial and Management Optimization, 12(3), 1009-1029.

Paul, S. K., Sarker, R., \& Essam, D. (2017). A Quantitative Model for Disruption Mitigation in a Supply Chain. European Journal of Operational Research, 257(3), 881-895.

Paul, S. K., Sarker, R., \& Essam, D. (2018). A reactive mitigation approach for managing supply disruption in a three-tier supply chain. Journal of Intelligent Manufacturing, 29(7), 1581-1597. doi:10.1007/s10845-016-1200-7

Paul, S. K., \& Shams, R. (2018). A quantitative and simulation model for managing sudden supply delay with fuzzy demand and safety stock. International Journal of Production Research, 56(13), 4377-4395.

Riglietti, G., \& Aguada, L. (2018). Supply chain resilience report. The Business Continuity Institute.

Sarkar, A., Mohapatra, P. K. J., Chaudhary, A., Agrawal, A., Mandal, A., \& Padhi, S. S. (2013). 
Single or Multiple Sourcing: A Method for Determining the Optimal Size of the Supply Base. Technology Operation Management, 3(1-2), 17-31. doi:10.1007/s13727-013-00136

Serel, D. A. (2015). Production and pricing policies in dual sourcing supply chains. Transportation Research Part E: Logistics and Transportation Review, 76, 1-12.

Sheffi, Y., \& Rice, J. B. J. (2005). A supply chain view of the resilient enterprise. MIT Sloan Management Review, 47(1), 41-48.

Silbermayr, L., \& Minner, S. (2014). A multiple sourcing inventory model under disruption risk. International Journal of Production Economics, 149, 37-46.

Snyder, L. V, Atan, Z., Peng, P., Rong, Y., Schmitt, A. J., \& Sinsoysal, B. (2016). OR/MS models for supply chain disruptions: a review. IIE Transactions, 48(2), 89-109.

Tang, C. (2006). Robust strategies for mitigating supply chain disruptions. International Journal of Logistics: Reserach and Applications, 9(1), 33-45.

Tang, O., \& Nurmaya Musa, S. (2011). Identifying risk issues and research advancements in supply chain risk management. International Journal of Production Economics, 133(1), 25-34. doi:10.1016/j.ijpe.2010.06.013

Thun, J.-H., \& Hoenig, D. (2011). An empirical analysis of supply chain risk management in the German automotive industry. International Journal of Production Economics, 131(1), 242-249.

Tomlin, B. (2006). On the Value of Mitigation and Contingency Strategies for Managing Supply Chain Disruption Risks. Management Science, 52(5), 639-657.

Wagner, S., \& Bode, C. (2008). An empirical examination of supply chain performance along several demensions of risk. Journal of Business Logistics, 29(1), 307-325.

Wakolbinger, T., \& Cruz, J. M. (2011). Supply chain disruption risk management through strategic information acquisition and sharing and risk-sharing contracts. International Journal of Production Research, 49(13), 4063-4084.

Wieland, A., \& Wallenburg, C. M. (2012). Dealing with supply chain risks: Linking risk management practices and strategies to performance. International Journal of Physical Distribution \& Logistics Management, 42(10), 887-905.

Wu, T., Blackhurst, J., \& Chidambaram, V. (2006). A model for inbound supply risk analysis. Computers in Industry, 57(4), 350-365.

Wu, T., Blackhurst, J., \& O'grady, P. (2007). Methodology for supply chain disruption analysis. International Journal of Production Research, 45(7), 1665-1682.

Xia, Y., Yang, M. H., Golany, B., Gilbert, S. M., \& Yu, G. (2004). Real-time disruption management in a two-stage production and inventory system. IIE Transactions, 36, 111125.

Xiao, T., Qi, X., \& Yu, G. (2007). Coordination of supply chain after demand disruptions when retailers compete. International Journal of Production Economics, 109(1-2), 162-179.

Xu, J., Zhuang, J., \& Liu, Z. (2016). Modeling and mitigating the effects of supply chain disruption in a defender-attacker game. Annals of Operations Research, 236(1), 255-270.

Yang, J., Oi, X., \& Yu, G. (2005). Disruption management in production planning. Naval Research Logistics, 52, 420-442.

Yu, H., Zeng, A. Z., \& Zhao, L. (2009). Single or dual sourcing: decision-making in the presence of supply chain disruption risks. Omega, 37(4), 788-800.

Zsidisin, G. a., Panelli, A., \& Upton, R. (2000). Purchasing organization involvement in risk assessments, contingency plans, and risk management: an exploratory study. Supply Chain Management: An International Journal, 5(4), 187-198. doi:10.1108/13598540010347307

Zsidisin, G. A., \& Smith, M. E. (2005). Managing supply risk with early supplier involvement: a case study and research propositions. Journal of Supply Chain Management, 41(4), 4457. 


\section{Appendices}

\section{Appendix A. Modeling for sudden production disruption}

Appendix A formulates the mathematical model for generating the recovery plan after a sudden production disruption. The model considers the costs of production, delivery, holding, raw materials, backorder, and lost sales, and determines the revenue from the selling price. Finally, the model is formulated as a constrained mathematical programming problem in which the total profit to be maximized is subject to constraints from capacity, demand, delivery, and inventory.

Total production cost $=\frac{C_{p}}{r} \sum_{i=1}^{n} X_{i}$

Total rejection cost $=C_{R}\left(\frac{1}{r}-1\right) \sum_{i=1}^{n} X_{i}$

Total inspection cost $=\frac{C_{I} C_{p}}{r} \sum_{i=1}^{n} X_{i}$

Cost of interest and depreciation $=n a A^{-b} r^{c}$

Total raw material cost $=\sum_{i=1}^{n} C_{r} Z_{i}=\frac{N C_{r}}{r} \sum_{i=1}^{n} X_{i}$

Raw material holding cost $=\frac{1}{2 r} H_{1} N \sum_{i=1}^{n} X_{i}$

Total delivery cost $=\sum_{i=1}^{n} C_{d} Y_{i}$

Total ending inventory holding cost $=H_{2} \sum_{i=1}^{n} e_{i}$

Backorder cost $=B \sum_{i=2}^{n}(i-1)\left(X_{i}-A P_{i}\right)$

Lost sales cost $=L\left(\sum_{i=1}^{n} A P_{i}-\sum_{i=1}^{n} X_{i}\right)$

Total revenue $=S \sum_{i=1}^{n} X_{i}$

\section{Final mathematical model}

Total profit $=$ total revenue - total costs, is the objective function and to be maximized, which is obtained using equations (A1) - (A11) and subject to constraints (A12) - (A20).

$e_{i} \geq E_{i} ; \forall i$ [Constraint of ending inventory]

$b_{i} \geq B_{i} ; \forall i$ [Constraint of beginning inventory]

$X_{1} \leq r\left(P-T_{d p} * P\right)$ [Limitation of production quantity in first period]

$X_{i} \leq r P ; \forall i \neq 1$ [Limitation of production quantity in each period]

$X_{i} \geq A P_{i} ; \forall i \neq 1$ [Constraint for production in recovery plan]

$\sum_{i=1}^{n} X_{i} \leq \sum_{i=1}^{n} D_{i}+b_{n+1}-b_{1}$ [Limitation of total production quantity]

$\sum_{i=1}^{n} A P_{i}-\sum_{i=1}^{n} X_{i} \geq 0$ [Constraint of lost sales quantity]

$\sum_{i=1}^{n} Y_{i} \leq \sum_{i=1}^{n} D_{i}$ [Limitation of total delivery]

$X_{i}, Y_{i}, Z_{i} \geq 0$ and integer; $\forall i$ [Non-negativity constraint] 


\section{Appendix B. Modeling for sudden supply disruption}

In this appendix, a constrained mathematical programing model is formulated for generating the recovery plan after a sudden supply disruption in which the total profit is maximized subject to the constraints from capacity, demand, delivery, and inventory.

Total production cost $=\frac{C_{p}}{r} \sum_{i=1}^{n} X_{i}$

Total rejection cost $=C_{R}\left(\frac{1}{r}-1\right) \sum_{i=1}^{n} X_{i}$

Total inspection cost $=\frac{C_{I} C_{p}}{r} \sum_{i=1}^{n} X_{i}$

Cost of interest and depreciation $=n a A^{-b} r^{c}$

Total raw material cost $=\sum_{i=1}^{n} C_{r} Z_{i}=\frac{N C_{r}}{r} \sum_{i=1}^{n} X_{i}$

Raw material holding cost $=\frac{1}{2 r} H_{1} N \sum_{i=1}^{n} X_{i}$

Total delivery $\operatorname{cost}=\sum_{i=1}^{n} C_{d} Y_{i}$

Total ending inventory holding cost $=H_{2} \sum_{i=1}^{n} e_{i}$

Backorder cost $=B \sum_{i=2}^{n}(i-1)\left(X_{i}-A P_{i}\right)$

Lost sales cost $=L\left(\sum_{i=1}^{n} A P_{i}-\sum_{i=1}^{n} X_{i}\right)$

Total revenue $=S \sum_{i=1}^{n} X_{i}$

\section{Final mathematical model}

Total profit $=$ total revenue - total costs, is the objective function and to be maximized, which is obtained using equations (B1) - (B11) and subject to constraints (B12) - (B20).

$e_{i} \geq E_{i} ; \forall i$ [Constraint of ending inventory]

$b_{i} \geq B_{i} ; \forall i$ [Constraint of beginning inventory]

$X_{1} \leq r\left(P-T_{d s} * P\right)$ [Limitation of production quantity in first period]

$X_{i} \leq r P ; \forall i \neq 1$ [Limitation of production quantity in each period]

$X_{i} \geq A P_{i} ; \forall i \neq 1$ [Constraint for production in recovery plan]

$\sum_{i=1}^{n} X_{i} \leq \sum_{i=1}^{n} D_{i}+b_{n+1}-b_{1}$ [Limitation of total production quantity]

$\sum_{i=1}^{n} A P_{i}-\sum_{i=1}^{n} X_{i} \geq 0$ [Constraint of lost sales quantity]

$\sum_{i=1}^{n} Y_{i} \leq \sum_{i=1}^{n} D_{i}$ [Limitation of total delivery]

$X_{i}, Y_{i}, Z_{i} \geq 0$ and integer; $\forall i$ [Non-negativity constraint] 


\section{Appendix C. Heuristic 2: Generating recovery plan for a sudden production disruption}

This appendix shows heuristic steps to generate recovery plan for a sudden production disruption.

Step 1: Input data for ideal plan.

Step 2: Determine and record ideal plan.

Step 3: Determine spare capacity $\left(S C_{i}\right)$ of each period.

Step 4: Input production disruption start time $\left(t_{s}\right)$ and duration $\left(T_{d p}\right)$ and determine loss of production $=T_{d p} * r P$.

Step 5: If $0 \leq T_{d p} * r P \leq S C_{1}$, then

Step 6: For $k=2$ to $n$

$$
X_{i}=A P_{i} ; i=1,2,3 \ldots n
$$

For $\sum_{j=1}^{k-1} S C_{j}<T_{d p} * r P \leq \sum_{j=1}^{k} S C_{j}$

$$
\begin{aligned}
& \text { If } B \leq \frac{L}{k-1}, \text { then } \\
& X_{1}=A P_{1}+S C_{1}-T_{d p} * r P \\
& X_{i}=A P_{i}+S C_{i} ; i=2,3 \ldots k-1 \\
& X_{k}=A P_{k}+T_{d p} * r P-\sum_{j=1}^{k-1} S C_{j} \\
& \quad X_{i}=A P_{i} ; i=k+1, k+2 \ldots n \\
& \quad \text { If } \frac{L}{k-1}<B \leq \frac{L}{k-2}, \text { then } X_{1}=A P_{1}+S C_{1}-T_{d p} * r P \\
& \quad X_{i}=A P_{i}+S C_{i} ; i=2,3 \ldots k-1 \\
& \quad X_{i}=A P_{i} ; i=k, k+1, k+2 \ldots n \\
& \ldots \ldots \ldots . . \\
& \text { If } \frac{L}{2}<B \leq L, \text { then } \\
& \quad X_{1}=A P_{1}+S C_{1}-T_{d p} * r P \\
& X_{2}=A P_{2}+S C_{2} \\
& X_{i}=A P_{i} ; i=3,4 \ldots n \\
& \text { If } B>L_{\text {then }} \\
& \mathrm{X}_{1}=\mathrm{AP}_{1}+\mathrm{SC}_{1}-\mathrm{T}_{\mathrm{d}} * \mathrm{rP} \\
& X_{i}=A P_{i} ; i=2,3 \ldots n
\end{aligned}
$$

Step 7: For $T_{d} * r P>\sum_{j=1}^{n} S C_{j}$

$$
\begin{aligned}
& \text { If } B \leq \frac{L}{n-1}, \text { then } \\
& X_{1}=A P_{1}+S C_{1}-T_{d p} * r P \\
& X_{i}=A P_{i}+S C_{i} ; i=2,3 \ldots n \\
& \text { If } \frac{L}{n-1}<B \leq \frac{L}{n-2}, \text { then } \\
& \mathrm{X}_{1}=\mathrm{AP}_{1}+\mathrm{SC}_{1}-\mathrm{T}_{\mathrm{dp}} * \mathrm{rP} \\
& X_{i}=A P_{i}+S C_{i} ; i=2,3 \ldots n-1 \\
& X_{n}=A P_{n}
\end{aligned}
$$

If $\frac{L}{2}<B \leq L$, then

$$
\begin{aligned}
& X_{1}=A P_{1}+S C_{1}-T_{d p} * r P \\
& X_{2}=A P_{2}+S C_{2} \\
& X_{i}=A P_{i} ; i=3,4 \ldots n
\end{aligned}
$$

If $B>L$, then

$$
X_{1}=A P_{1}+S C_{1}-T_{d p} * r P
$$




$$
X_{i}=A P_{i} ; i=2,3 \ldots n
$$

Step 8: Determine raw material required and final product delivery quantity.

$$
\begin{aligned}
& Y_{i}=B_{i}+X_{i}-E_{i} ; i=1,2,3 \ldots n \\
& Z_{1}=N * \frac{A P_{1}}{r} \\
& Z_{2}=\frac{1}{r}\left[N * X_{2}-N *\left(A P_{1}-X_{1}\right)\right] \\
& Z_{i}=N * \frac{X_{i}}{r} ; i=3,4 \ldots n
\end{aligned}
$$

Step 9: Determine total profit and different costs.

Step 10: Stop.

\section{Appendix D. Heuristic 3: Generating recovery plan for a sudden supply disruption}

This appendix shows heuristic steps to generate recovery plan for a sudden supply disruption.

Step 1: Input data for ideal plan.

Step 2: Determine and record ideal plan.

Step 3: Determine spare capacity $\left(S C_{i}\right)$ of each period.

Step 4: Input supply disruption duration $\left(T_{d s}\right)$ and determine loss of production $(L P)$.

Step 5: If $0 \leq L P \leq S C_{1}$, then

$$
X_{i}=A P_{i} ; i=1,2,3 \ldots n
$$

Step 6: For $k=2$ to $n$

$$
\begin{aligned}
& \text { For } \sum_{j=1}^{k-1} S C_{j}<L P \leq \sum_{j=1}^{k} S C_{j} \\
& \qquad \begin{array}{c}
\text { If } B \leq \frac{L}{k-1} \text {, then } \\
X_{1}=A P_{1}+S C_{1}-L P \\
X_{i}=A P_{i}+S C_{i} ; i=2,3 \ldots k-1 \\
X_{k}=A P_{k}+L P-\sum_{j=1}^{k-1} S C_{j} \\
X_{i}=A P_{i} ; i=k+1, k+2 \ldots n \\
\text { If } \frac{L}{k-1}<B \leq \frac{L}{k-2}, \text { then } \\
X_{1}=A P_{1}+S C_{1}-L P \\
X_{i}=A P_{i}+S C_{i} ; i=2,3 \ldots k-1 \\
X_{i}=A P_{i} ; i=k, k+1, k+2 \ldots n \\
\ldots \ldots \ldots . \\
\text { If } \frac{L}{2}<B \leq L, \text { then } \\
X_{1}=A P_{1}+S C_{1}-L P \\
X_{2}=A P_{2}+S C_{2} \\
X_{i}=A P_{i} ; i=3,4 \ldots n \\
X_{1}=A P_{1}+S C_{1}-L P \\
X_{i}=A P_{i} ; i=2,3 \ldots n
\end{array}
\end{aligned}
$$

Step 7: For $L P>\sum_{j=1}^{n} S C_{j}$

$$
\begin{aligned}
& \text { If } B \leq \frac{L}{n-1} \text {, then } \\
& X_{1}=A P_{1}+S C_{1}-L P \\
& \quad X_{i}=A P_{i}+S C_{i} ; i=2,3 \ldots n \\
& \text { If } \frac{L}{n-1}<B \leq \frac{L}{n-2}, \text { then } \\
& X_{1}=A P_{1}+S C_{1}-L P \\
& X_{i}=A P_{i}+S C_{i} ; i=2,3 \ldots n-1
\end{aligned}
$$




$$
\begin{gathered}
X_{n}=A P_{n} \\
\ldots \ldots \ldots \\
\text { If } \frac{L}{2}<B \leq L, \text { then } \\
X_{1}=A P_{1}+S C_{1}-L P \\
X_{2}=A P_{2}+S C_{2} \\
X_{i}=A P_{i} ; i=3,4 \ldots n \\
\text { If } B>L, \text { then } \\
X_{1}=A P_{1}+S C_{1}-L P \\
X_{i}=A P_{i} ; i=2,3 \ldots n
\end{gathered}
$$

Step 8: Determine raw material required and final product delivery quantity.

$$
\begin{aligned}
& Y_{i}=B_{i}+X_{i}-E_{i} ; i=1,2,3 \ldots n \\
& Z_{1}=N * \frac{A P_{1}}{r} \\
& Z_{2}=\frac{1}{r}\left[N * X_{2}-N *\left(A P_{1}-X_{1}\right)\right] \\
& Z_{i}=N * \frac{X_{i}}{r} ; i=3,4 \ldots n
\end{aligned}
$$

Step 9: Determine total profit and different costs.

Step 10: Stop.

\section{Appendix E. Heuristic for considering combined effect multiple disturbances}

A demand fluctuation occurs at the retailer end, a supply disruption at the supplier end, and a production disruption at the manufacturing plant. Multiple disturbances can happen together in a period, in which case their effects must be considered when formulating a recovery plan. We develop a heuristic to deal with multiple disturbances and use random data to develop multiple disturbance scenarios. The steps in Heuristic 4 for managing multiple disturbances in a period are presented below.

Step 1: Input data for ideal plan.

Step 2: Determine and record ideal plan.

Step 3: Determine spare capacity $\left(S C_{i}\right)$ of each period.

Step 4: Input demand fluctuation, supply disruption and/or production disruption scenario.

Step 5: Determine unfulfilled demand, $D_{u}=\delta+\left(T_{d s}+T_{d p}\right) * r P$

Step 6: For $D_{u}>0$

6.1 For $0 \leq D_{u} \leq S C_{1}$

If $B \leq L$, then

$$
\begin{aligned}
& X_{1}=A P_{1}+D_{u}-\left(T_{d s}+T_{d p}\right) * r P \\
& X_{i}=A P_{i} ; i=2,3 \ldots n
\end{aligned}
$$

If $B>L$, then

6.2 For $k=2$ to $n$

$$
X_{i}=A P_{i} ; i=1,2,3 \ldots n
$$

$$
\begin{aligned}
& \text { For } \sum_{j=1}^{k-1} S C_{j}<D_{u} \leq \sum_{j=1}^{k} S C_{j} \\
& \text { If } B \leq \frac{L}{k} \text {, then }
\end{aligned}
$$

$$
\begin{aligned}
& X_{1}=A P_{1}+S C_{1}-\left(T_{d s}+T_{d p}\right) * r P \\
& X_{i}=A P_{i}+S C_{i} ; i=2,3 \ldots k-1 \\
& X_{k}=A P_{k}+D_{u}-\sum_{j=1}^{k-1} S C_{j}
\end{aligned}
$$




$$
\begin{gathered}
X_{i}=A P_{i} ; i=k+1, k+2 \ldots n \\
\text { If } \frac{L}{k}<B \leq \frac{L}{k-1}, \text { then } \\
X_{1}=A P_{1}+S C_{1}-\left(T_{d s}+T_{d p}\right) * r P \\
X_{i}=A P_{i}+S C_{i} ; i=2,3 \ldots k-1 \\
X_{i}=A P_{i} ; i=k, k+1, k+2 \ldots n \\
\ldots \ldots \ldots . . . \\
\text { If } \frac{L}{2}<B \leq L, \text { then } \\
\mathrm{X}_{1}=\mathrm{AP}_{1}+\mathrm{SC}_{1}-\left(\mathrm{T}_{\mathrm{ds}}+\mathrm{T}_{\mathrm{dp}}\right) * \mathrm{rP} \\
X_{i}=A P_{i} ; i=2,3 \ldots n
\end{gathered}
$$

If $B>L$, then

6.3 For $D_{u}>\sum_{j=1}^{n} S C_{j}$

$$
X_{i}=A P_{i} ; i=1,2,3 \ldots n
$$

If $B \leq \frac{L}{n}$, then

$$
\begin{aligned}
& X_{1}=A P_{1}+S C_{1}-\left(T_{d s}+T_{d p}\right) * r P \\
& X_{i}=A P_{i}+S C_{i} ; i=2,3 \ldots n
\end{aligned}
$$

If $\frac{L}{n}<B \leq \frac{L}{n-1}$, then

$$
\begin{aligned}
& X_{1}=A P_{1}+S C_{1}-\left(T_{d s}+T_{d p}\right) * r P \\
& X_{i}=A P_{i}+S C_{i} ; i=2,3 \ldots n-1 \\
& X_{n}=A P_{n}
\end{aligned}
$$

If $\frac{L}{2}<B \leq L$, then

$$
\begin{aligned}
& X_{1}=A P_{1}+S C_{1} \\
& X_{i}=A P_{i} ; i=2,3 \ldots n
\end{aligned}
$$

If $B>L$, then

Step 7: For $D_{u}<0$

$$
X_{i}=A P_{i} ; i=1,2,3 \ldots n
$$

$$
\begin{aligned}
& X_{1}=A P_{1}-\left|D_{u}\right| \\
& X_{i}=A P_{i} ; i=2,3 \ldots n
\end{aligned}
$$

Step 8: Determine raw material required and final product delivery quantity.

$$
\begin{aligned}
& Y_{i}=B_{i}+X_{i}-E_{i} ; i=1,2,3 \ldots n \\
& Z_{i}=N * \frac{X_{i}}{r} ; i=1,2,3 \ldots n
\end{aligned}
$$

Step 9: Determine total profit and different costs.

Step 10: Stop. 